\title{
BIM-Based Digital Fabrication Process for a Free-Form Building Project in South Korea
}

\author{
Joo-sung Lee, ${ }^{1}$ Nahyun Kwon, ${ }^{1}$ Nam-hyuk Ham $\mathbb{D}^{0},{ }^{2}$ Jae-jun Kim, ${ }^{3}$ and Yong-han Ahn $\mathbb{D D}^{1}$ \\ ${ }^{1}$ Department of Architectural Engineering, Hanyang University, 55 Hanyangdaehak-ro, Sangrok-gu, Ansan-si, \\ Gyeonggi-do 15588, Republic of Korea \\ ${ }^{2}$ Department of Digital Architectural and Urban Engineering, Hanyang Cyber University, 220, Wangsimni-ro, \\ Seongdong-gu, Seoul 04763, Republic of Korea \\ ${ }^{3}$ Department of Architectural Engineering, Hanyang University, 220, Wangsimni-ro, Seongdong-gu, \\ Seoul 04763, Republic of Korea \\ Correspondence should be addressed to Nam-hyuk Ham; nhham@hycu.ac.kr
}

Received 30 November 2018; Revised 16 February 2019; Accepted 11 March 2019; Published 23 May 2019

Academic Editor: Mohammad R. Hosseini

Copyright ( $\odot 2019$ Joo-sung Lee et al. This is an open access article distributed under the Creative Commons Attribution License, which permits unrestricted use, distribution, and reproduction in any medium, provided the original work is properly cited.

\begin{abstract}
Since the concept of building information modeling (BIM) was introduced in South Korea in 2008, digital fabrication concerning free-form shapes and complex parametric information has been expanding owing to the development of BIM software and tools. However, the digital fabrication process is inadequate in terms of efficiency and productivity because of the need to convert from conventional two-dimensional (2D) drawings to a BIM design; this adversely affects the unified design, fabrication, installation, and inspection processes. Moreover, an optimized process has not been developed thus far because the productivity of digital fabrication has not been quantitatively verified for various projects in the field. This study proposes a BIM-based digital fabrication process for prefabricated parts of buildings. In addition, a productivity analysis method based on the queuing model is proposed using personnel input and performance calculation data to verify productivity. It is expected that the digital fabrication process and productivity analysis model proposed here will be applied to complex digital fabrication works.
\end{abstract}

\section{Introduction}

The main trend of the construction industry in the 21 st century is the creation of different spaces to improve the quality of human life and in forms that were previously unavailable to meet various user needs [1]. These needs have increasingly decided that the buildings be massive and the shapes be more complex; thus, the design of free-form and complex elements, manufacture of building components, and construction technology at the site must be supported to meet these needs [2]. Existing architectural techniques and paradigms are mostly available only in fragments, such as the optimal design technology for complex structures, techniques for fabrication of components, and precise installation technology. Therefore, the cost and time requirements for design, fabrication, and construction of complex types of structures will increase, eventually leading to construction errors and deterioration of building quality [3]. However, since the BIM concept was introduced in Korea in 2008, efforts have been made to overcome the problem of productivity degradation in the life cycles of construction projects [4].

Building information modeling (BIM) technology has been rapidly replacing conventional construction models, such as two-dimensional computer-aided design (2D CAD), paper documents, and Excel chart-based schedules, by improving the technical level of construction automation, introducing BIM-based innovations, and application of integrated project delivery (IPD) method in several countries. Digital fabrication is one such technology developed through the application of BIM and virtual design and construction (VDC) methods in the construction industry. Through BIM-based digital fabrication, designers, builders, and manufacturers of construction materials can perform 
detailed design and examination of the products to be fabricated as digital objects $[5,6]$.

BIM can integrate design, manufacturing, and construction processes to increase the level of transparency and interoperability among partners in construction projects that use prefabricated components [7]. Based on this advantage, BIM-based digital fabrication technology simplifies the procurement process in construction and improves the productivity of the workflow between designers, builders, and those involved in the manufacturing of construction components [8]. Moreover, from a fabrication productivity perspective, construction member manufacturers can utilize the data input from BIM objects to assist the fabrication process, and these are parametric data that are not provided by conventional 2D-based fabrication methods [8]. Automatic member shape recognition and fabrication are possible by inputting parametric BIM fabrication data into the member production process of the computerized numerical control (CNC) machine.

Despite this advantage, the digital fabrication process remains very inefficient in South Korea. In particular, although the level of digital fabrication requirement is very high for free-form buildings because each material has its own free-form shape, development of the elementary technologies required for actual fabrication and construction has been slow. Owing to these technical limitations, optimized processes or management methodologies for the life cycle management of free-form construction members, including design, fabrication, installation, and construction, are not sufficient, despite the rising demand for free-form buildings in South Korea. This affects the cost, construction period, and quality of projects.

Therefore, this study aimed to establish the life cycle process, including design, fabrication, and construction, of free-form structural members that are components of freeform buildings. Moreover, the proposed digital fabrication process for free-form construction members was implemented in an actual building based on a case study, which allowed for technical verification and productivity evaluation, as well as verification of the productivity of the implemented process.

\section{Literature Review}

2.1. Prefabrication of Construction Project. The prefabrication method in the construction industry is a way to reduce the overall project schedule since the processes at the factory and the on-site fields are carried out simultaneously. This advantage can be obtained by simultaneously running a large number of processes on-site and at the factory, compared to the on-site process, in which all tasks are performed in order [9]. This enables the contractor to actively utilize the prefabrication method for projects with an extremely short site schedule and complicated processes [9]. Prefabrication also helps to reduce costs by preventing the waste of materials due to poor field processing and through the repeated training of workers $[10,11]$. In addition, previous studies found that the use of prefabrication methodologies improved the quality of construction.
Digital applications and IT technologies can significantly improve the quality of construction by accurately reflecting the initial design and entering this design in the fabrication equipment [12-15]. In addition, prefabrication has the effect of reducing the wastage of resources by reducing the warehousing space, improving material quality, and optimizing the supply chain [7].

2.2. Digital Fabrication. Digital fabrication refers to a methodology that systematically manages all processes, such as generation, design, material processing, and construction of a structure that is intended to be produced by utilizing digital tools [16]. Digital fabrication technology is primarily used in specific projects, such as freeform buildings. In such projects, fabrication processes that exceed the conventional construction production methods are created through design goals and technical innovations [17]. The digital fabrication process of a construction project is generally classified as additional fabrication, and it is based on computer-based design methods and robotic-based production processes [18]. In particular, for the construction of free-form parts, various members are processed and assembled through additional fabrication processes that utilize industrial robots [19]. Owing to the recent development of digital technologies and the introduction of computer-based fabrication, buildings with very complex designs can also be realized [20].

\subsection{Implementation Cases and Benefits of BIM-Based Digital} Fabrication. A representative case of the use of digital technology for implementing digital fabrication is BIM. However, the application of BIM is determined by the characteristics of the project and can be limited to simple conversions of $2 \mathrm{D}$ CAD into a three-dimensional (3D) model or it can be more complex as in an ideal case in which design, fabrication, and construction are integrated and maintenance is considered [21]. Won et al. [22] conducted a case study on a collaborative organization and information management method based on a free-form project. Frank Gehry first applied CATIA, a design software program primarily used for the design of airplanes or automobiles, to construction in the Fish project (1991-1992) and aggressively utilized it for the $3 \mathrm{D}$ representation of curved shapes and the production process of construction members. Moreover, from the perspective of project information management, assembling one integrated team with designers and constructors for the 3D model constructed through CATIA improved the completeness of the design and contributed to the manufacturing of components and on-site construction. In particular, in the Bilbao Guggenheim Museum project (1991-1997), approximately 50,000 2D drawings were automatically created using a $3 \mathrm{D}$ model and were provided to the project participants.

Jang and Lee [23] analyzed the effect of applying multitrade prefabrication, in which multitrade mechanical, electrical, and plumbing (MEP) elements were preassembled in a factory, for construction instead of using the existing 
prefabrication method applied to a single process, and they also analyzed the technical requirements for this. Skanska USA reported that productivity increased by approximately $300 \%$, and the construction period was reduced by eight weeks in the Miami Valley hospital project by applying multitrade prefabrication to the corridor rack and bathroom pods [24]. Mortenson [25] reported that the total construction period was reduced by approximately $15 \%$, but the construction cost increased by approximately $6 \%$ through the application of multitrade prefabrication in the Saint Joseph Heritage project.

\subsection{Limitations of Existing Research on Digital Fabrication.} Despite the abovementioned advantages of digital fabrication, few studies on productivity factors, such as reduction of schedules, quality, and resource reduction during the manufacturing and construction stages, have been conducted. This is because the definition or efficiency of the digital fabrication life cycle process has never been verified, despite interest in implementing building element technology using digital fabrication [26]. In addition, the limitations of contracts, participants, organizations, and technologies hinder the unification and utilization of BIM data in digital fabrication, and as a result, the efficiency of BIM utilization is extremely low [27]. This is essentially owing to the absence of a methodology and technical limitations for managing processes based on BIM data throughout the fabrication life cycle [28].

\subsection{Research on the Productivity of Digital Fabrication.} Numerous studies have been conducted to measure the benefits of the BIM-based digital fabrication work process mentioned in Section 2.2, i.e., cost, construction period, and quality.

Jang and Lee [29] conducted a case study on the multitrade corridor rack prefabrication case project. They proposed a prefabrication process for the corridor MEP rack and analyzed its effectiveness using details of the process, productivity, and economic efficiency. de Soto et al. [30] proposed a new methodology for the automatic production of complex concrete walls in the field. They found that the process of the wall work changed when a concrete pouring robot was used and verified the effects of the CYCLONE discrete event simulation system on the cost and time to validate the process. Fazel and Izadi [31] proposed a work methodology for a free-form modular surface using a headmounted display visualizing an augmented reality for accuracy and construction period reduction of masonry work and verified the quality of the augmented-reality-based HMD methodology based on the visualized augmented reality coordinates and the coordinates of the actual masonry. Hamid et al. [8] proposed a CNC machine utilization methodology using a BIM-based digital fabrication model for woodwork. In particular, they proposed a CNC utilization methodology using a three-step cycle including process-level knowledge, component-level knowledge, and object development and validated the methodology through component fabrication. Knippers [32] redefined the role of the architect and proposed a new process for digital fabrication and analyzed a case that reflected these proposals. Li et al. [33] proposed a prefabrication production process for housing (RBL-PHP) using the RFID, BIM, and Lean methods and performed a simulation composed of steps, such as the prefabricated production of the structure, constraint identification, standardized work, and RBIMP, to verify the proposed process. Nahangi and Haas [34] proposed a three-step model (preprocessing, registration, and condition assessment) for $3 \mathrm{D}$ quality examination to perform quality and compliance verifications in the prefabrication phase of building piping. Wang et al. [35] classified the BIM-based framework for a unified process of the design-construction phases for the MEP system layout into the design, fabrication, and construction phases. Said [36] proposed a prefabrication applicability review model of electrical work.

The previous studies did not present a process for the entire life cycle, including basic design, shop design, prefabrication, and installation. The effects of the methods proposed in these studies were verified through case analysis, statistical analysis, and simulations.

2.6. Queuing Model. The queuing theory has been used in different research areas. Queuing systems are expressed using several types of queuing models [37]. Customers arrive at a queuing system individually and randomly to receive services. If a customer cannot receive services immediately upon arrival, the customer waits in a queue. Normally, one or more servers provide services. Each customer receives services from one of the servers and leaves the system. The queuing theory can be utilized to efficiently analyze the workflow, which is a network of various activities [38]. In the queuing system, the times between the arrivals of customers are referred to as the interarrival times. When sufficient data on the arrival of customers are collected, the average number of arriving customers per unit time can be estimated. Unlike conventional performance measurement tools, the performance and effectiveness measurement method based on the queuing model can measure the work of service providers at the request of customers based on time and manpower. It is, therefore, possible to measure practical work productivity. Ham and Kim [39] analyzed the performance of BIM personnel who stayed on the construction site for the construction phase of a BIM application project. They focused on the requests for information (RFIs) of the project participants considering the characteristics of the queuing model. Kim et al. [40] found that costs may occur owing to the waiting times of the project participants depending on the performance of the BIM personnel.

Many studies have indicated that the queuing model is an optimized tool for analyzing the performance of a construction process and output. Queue performance measures, such as waiting time and queue length, are some of the most important simulation outputs in construction management for analyzing the balance between different resources [41]. Furthermore, queue performance measures can make the estimation of important outputs of the construction performance simulation reliable as they use 
appropriate quantitative modeling of activity duration and input resources [41]. Queue performance measures, such as average queue length and waiting time, are important for finding bottlenecks and optimizing the amount of resources for construction projects [42]. The digital fabrication process is nonquantitative, and it deals with different types of factors, and thus, performance simulation using the queuing model is an optimized methodology for investigating the productivity and efficiency of processes [30].

\section{Research Methodology}

3.1. Research Approach: Exploratory Case Study. In this study, a digital fabrication process formulated through case analyses and an evaluation method based on the queuing model that is capable of analyzing the construction process is proposed. According to Gerring [43], case analysis is "an intensive study of a single unit for the purpose of understanding a larger class of (similar) units." From a general perspective, case analysis is typically a research methodology that enables empirical and plentiful explanations and analysis of one phenomenon occurring in a specific case based on the diversity of data sources [44]. Therefore, a law, as a theoretical proposition and logical configuration, can be defined through the evidence derived from a case, and the methodology can be used for quantitative and qualitative evidence collection $[45,46]$.

This paper comprises a literature review, proposal of digital fabrication process for a free-form podium, case analysis, and productivity analysis for the proposed digital fabrication process, as shown in Figure 1.

3.2. Implemented Case: S Tower at South Korea. S Tower is located in Seoul, South Korea. It is a very tall building with 123 floors and a height of $555 \mathrm{~m}$. It was designed by $\mathrm{K} \& \mathrm{~B}$ Architects and constructed by L E\&C. L CM company performed the CM. Digital fabrication was applied to the podium region (approximately $8,200 \mathrm{~m}^{2}$ ) of the $\mathrm{S}$ Tower.

A CNC T-BAR shape control system was selected for the precise shape control of the podium region with a free form. The CNC T-BAR shape control system applied the member concept of a section shape, which is used for producing the curved structures of airplanes and ships, to construction projects [47]. This system precisely controls all the coordinate points of a curved surface with vertical and horizontal variable thickness attributes. After developing the cross section formed by cutting a free-form curved surface into a curved shape, the system processes a steel plate with CNC equipment (e.g., laser, router, and plasma). The system performs the mass production (or fabrication) of the flange, web, and connecting members of vertical and horizontal T-bars with various curvatures.

\section{Digital Fabrication Process for Free-Form Podium}

4.1. Digital Fabrication Process Proposal. The case analyzed in this study was the free-form paneling and subwork installed in the podium region of the $\mathrm{S}$ Tower. The process for performing digital fabrication was developed in the planning phase.

During on-site construction, the traditional construction method, prefabrication is not performed, and direct on-site installation is performed. This causes many problems, such as quality degradation, cost increase, weather and ambient air impacts, and inconvenient work site conditions caused by construction period delays and quantity increases. As such problems largely occur with free forms, complex shapes, and multitrade objects, design or construction is generally difficult. Prefabrication is considered for these parts, and the digital fabrication method can be applied to achieve the prefabrication of free-form or complex structures. Therefore, while the conventional construction method is a simpler design-construction method, prefabrication is added to the construction processes, including the manufacturing work.

The case studied herein was part of a free-form panel fabrication. In particular, it involves significant difficulties, such as the derivation of a design reflecting $100 \%$ of the designer's intention for the free-form panel with a secondary curved surface; selection of an appropriate structural system for supporting the design; derivation of drawings with numerical data, such as accurate coordinates, from the design; creation of shop documents for panel fabrication based on the basic design; shop model creation and utilization for CNC machine utilization; on-site construction consistent with the drawings; precise quality control for fabrication and construction; and measurement of the accuracy improvement.

To overcome the difficulties of digital fabrication, a BIMbased model capable of implementing the accurate shape as intended and an implementation process that utilizes the unified data based on the BIM model must be used. In particular, an optimized work plan that accounts for the personnel and the construction period of each task involved in the digital fabrication task during the project life cycle, including design, fabrication, on-site delivery, and installation, is required. As shown in Figure 2, a digital fabrication process was developed to overcome various difficulties expected in the case project.

\subsection{Case Application of the Digital Fabrication Process}

4.2.1. Step 1: Design of Free-Form Part Shape and Panels. When a podium is designed in the design phase, a detailed construction method is not typically considered. Therefore, the design model as shown in Figure 3 does not include specific information for construction.

However, in the construction phase, the constructability, economic efficiency, and quality must be considered. Digital fabrication for the podium region was performed for seven months, including fabrication design, member fabrication, and construction. In the fabrication design phase, the model was optimized by dividing the exterior panel of the free-form region into panels composed of curved surfaces in two directions, flat panels and curved surface-plane connection panels, as presented in Table 1. 

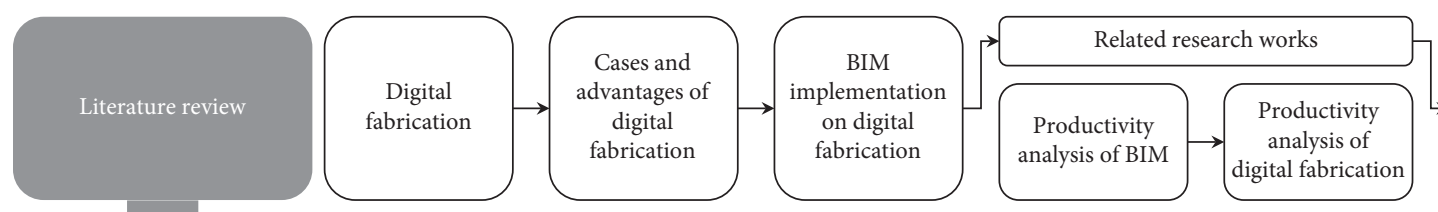

Queuing

model

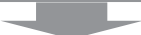
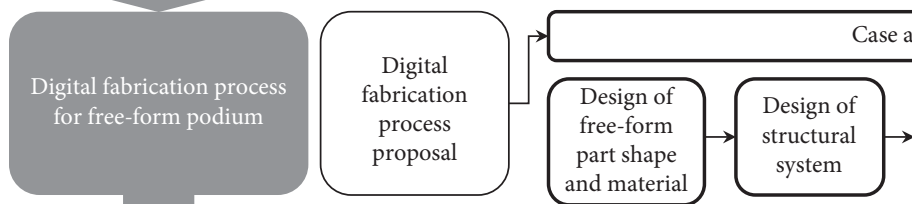

Case application of the digital fabrication process

-
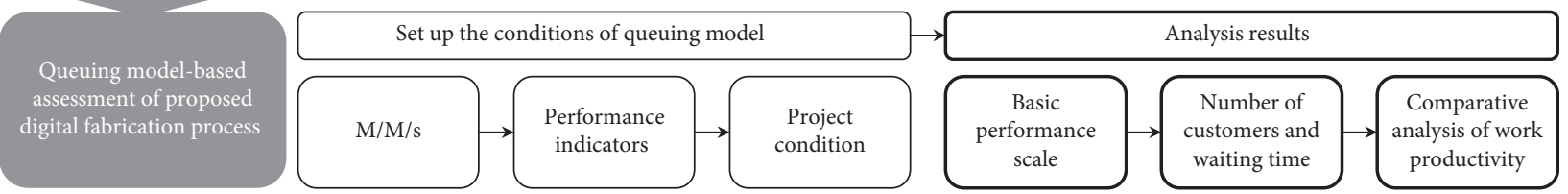

FiguRE 1: Research process.

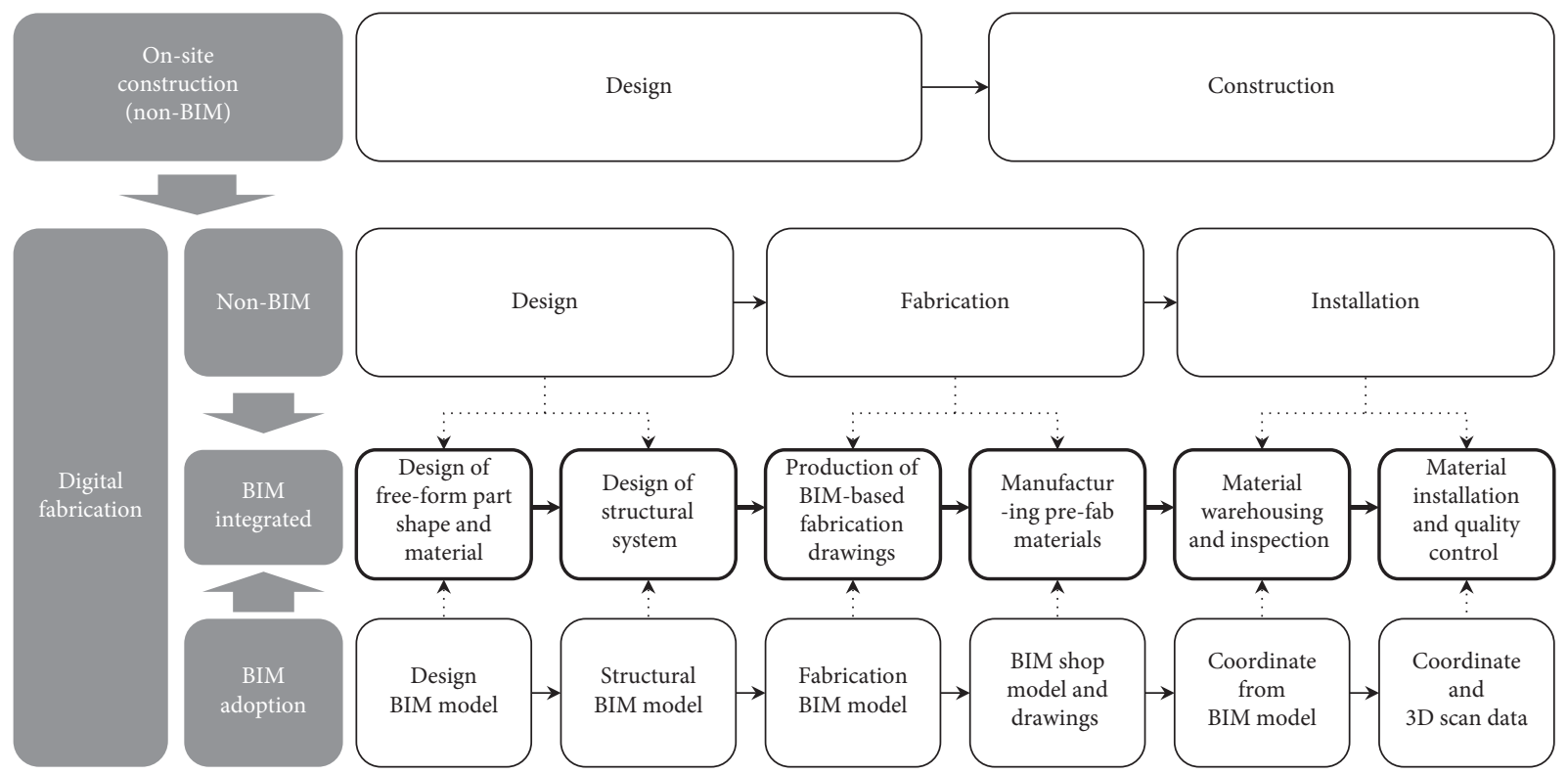

Figure 2: Proposed digital fabrication process.

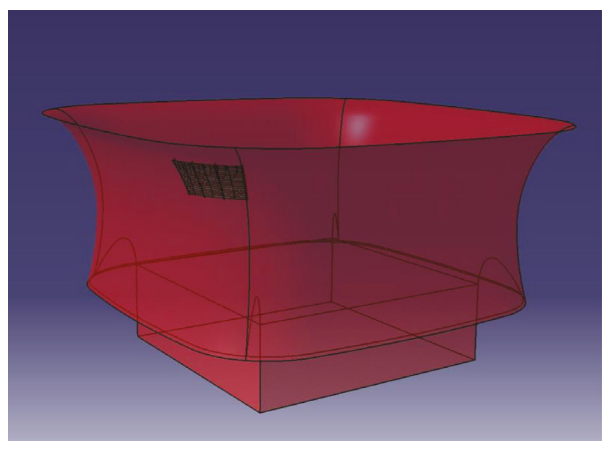

(a)

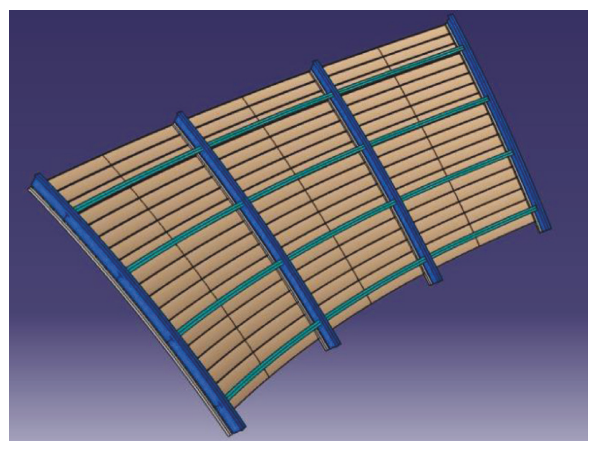

(b)

FIgURE 3: Design model: (a) preliminary concept model and (b) DD stage design model. 
Table 1: Panel optimization of upper and lower surfaces.

\begin{tabular}{lcc}
\hline Category & Upper surface & Lower surface \\
\hline Two-way irregular panels & $1,867 \mathrm{~m}^{2}$ & $240 \mathrm{~m}^{2}$ \\
Flat and irregular panels & $465 \mathrm{~m}^{2}$ & $73 \mathrm{~m}^{2}$ \\
One-way irregular panels & $2,555 \mathrm{~m}^{2}$ & $1,688 \mathrm{~m}^{2}$ \\
Optimization area (\% of & $2,332 \mathrm{~m}^{2}$ & $313 \mathrm{~m}^{2}$ \\
gross area) & (approx. 48\%) & (approx. 16\%) \\
\hline
\end{tabular}

This is the basic repetition procedure for a production process used to construct a large number of panels and maximize quality and productivity. Figure 4 shows the shape optimization model of the podium region. This becomes the reference surface of the final materials, such as the NT panels and reveal. Moreover, through this reference surface, the structural members and accessories for controlling the shapes of the final materials are precisely fabricated.

\subsubsection{Step 2: Design of the Structural System Controlling the} Panel Shape. The coordinates for the free-form curved surface of the NT panel were controlled by the CNC T-BAR shape control system. First, the secondary structure attached to the primary structure was designed, as shown in Figure 5. The primary structure was designed and engineered based on the free-form curved surface shape from Step 1. This history is utilized for producing fabrication drawings, and it provides detailed processing information (e.g., bending and bolt and nut positions) for factory fabrication. Moreover, to remove the clashes between the structural system and MEP materials, the BIM-based clash detection step was performed using the Autodesk Navisworks manager, as shown in Figure 6.

Based on the secondary structure, vertical and horizontal CNC T-BAR shapes for controlling the free-form curved surface shape of the NT panel were designed, as shown in Figure 7. Moreover, the details of the CNC form plate for controlling the position of the NT panel along with the reveal and NT panel, which are finishing materials, were examined. The NT panel, a finishing material, and the CNC form plate, a structural member, were connected, and the details of the adjustment bracket for precisely controlling the shape were examined.

An integrated fabrication model with the construction method and details for precisely controlling the free-form curved surface shape was completed, as shown in Figure 8.

\subsubsection{Step 3: Production of BIM-Based Fabrication Drawings.}

The fabrication model for which the construction method and details were examined was utilized to produce drawings for factory fabrication. Table 2 lists the members fabricated in factories for this case project. The total quantity of the members was 29,654. When the adjustment brackets and small members were included, 35,000 or more members needed to be produced.

Digital fabrication companies provided fabrication drawings and quality criteria (e.g., welding and bolt/nut fastening methods) to the companies responsible for the fabrication and construction of each member using the fabrication model. As the members were produced by different companies, the fabrication drawings for factory fabrication, such as the planar figure, were transmitted according to the classification of the member set unit (e.g., the CNC T-BAR and reveal) as shown in Figure 9. The detailed drawings for fabrication of the CNC T-BAR and secondary steel structure were extracted from the fabrication BIM model, as shown in Figure 10.

\subsubsection{Step 4: Manufacturing Prefabrication Materials Using} Digital Information. When the subcontractors responsible for the fabrication of each member received the fabrication drawings, the members were produced through various fabrication methods. In this process, automatic production was performed using a CNC machine, and engineers produced the members in accordance with the fabrication drawings and quality criteria. For example, for the production of the CNC T-BAR, the planar figures of the main members, such as the PLANGE (59A03VW) and WEB (59A03VF), along with the unit member information for connecting these two members (59A03V_U1, 59A03V_U2, and 59A03V_U3) were required, as shown in Figure 11. Moreover, planar figures of the PLANGE (59A03VW2) and WEB (59A03VF2) for the stiffener together with the unit member information for connecting these two members (59A03VS1, 59A03VS2, 59A03VS3, 59A03VS4, and 59A03VS5) were also required. Thus, various data, as shown in Figure 11, are required for fabricating a single unit member, and the information required for quality control must also be calculated from the integrated fabrication model created by professional construction companies. In this process, the professional construction companies provided various types of data required for fabrication drawing production, quality control criteria provisions, and material inspection criteria.

4.2.5. Step 5: Material Warehousing and Inspection. A photograph of each member fabricated in the factories as received is shown in Figure 12, and quality inspection was performed by the product number and the coordinate information extracted from the fabrication model, as listed in Table 3.

\subsubsection{Step 6: Material Installation and Quality Control}

(1) Simulation and 1:1 Mock-Up. In the construction phase, a construction simulation was performed to improve the workers' understanding of the entire process before construction, as shown in Figure 13. Issues with quality and constructability were examined in advance by performing a partial 1:1 mock-up in the section with the highest construction difficulty, as shown in Figure 14. After these issues were solved, the production of several tens of thousands of fabrication drawings began, and the CNC machine configuration, member fabrication, and construction for member production were performed.

(2) Installation. In the actual construction process, the process in which fabrication drawings are produced from the 


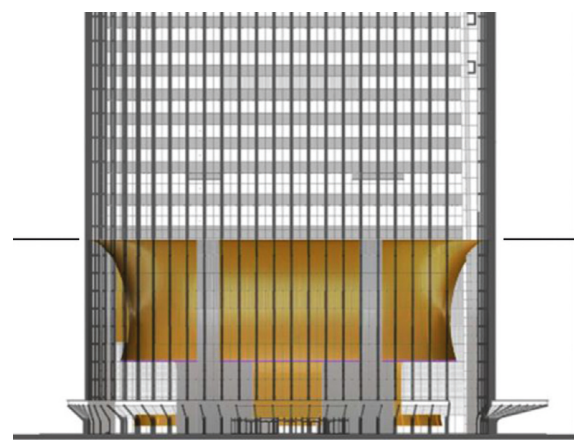

(a)

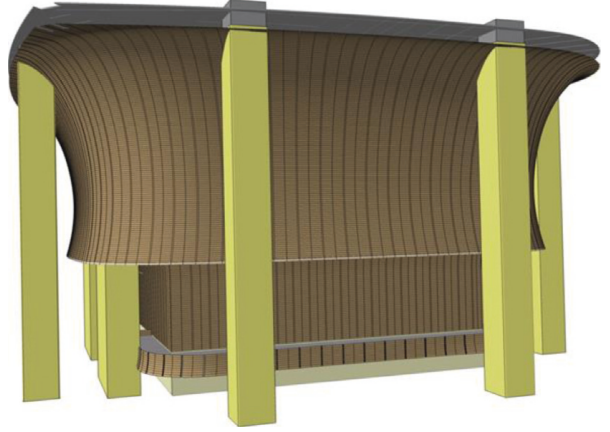

(b)

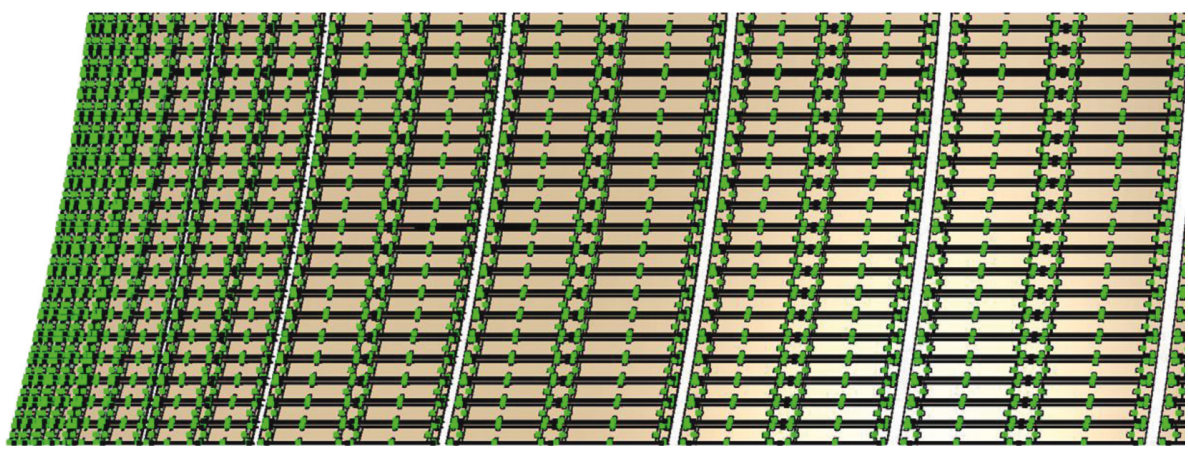

(c)

FIGURE 4: Surface optimization model of the podium.

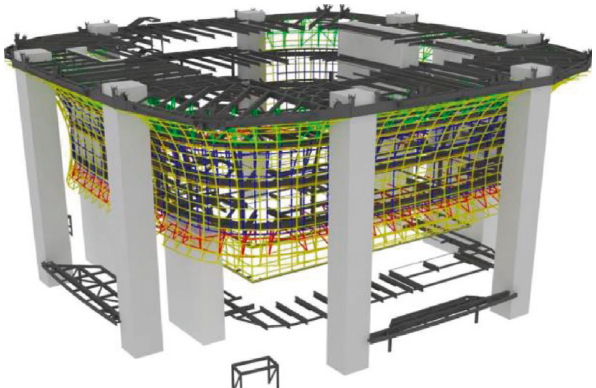

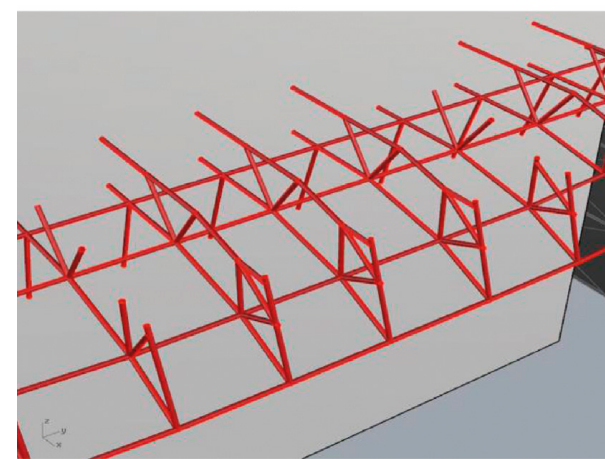

(a)

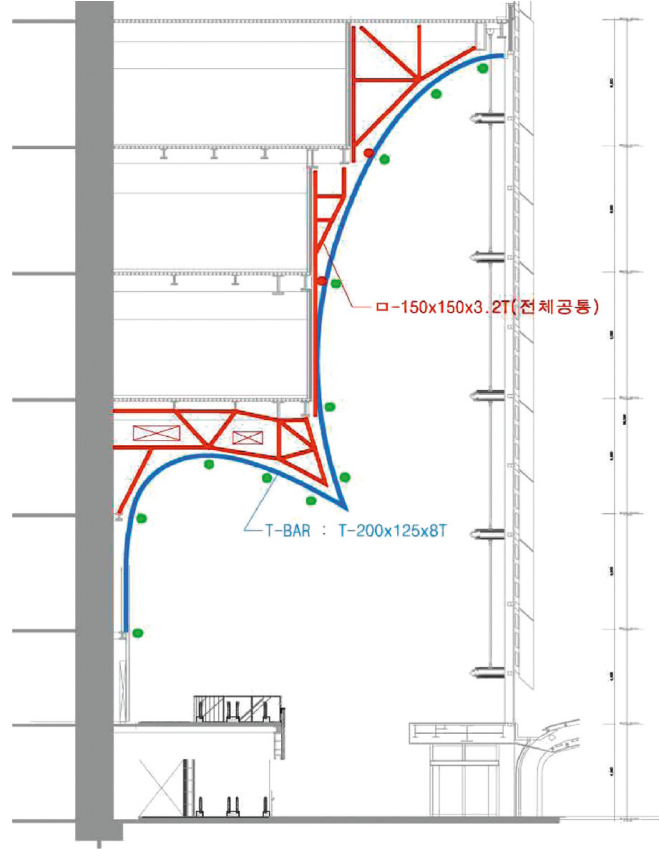

(b)

FIgURE 5: (a) SSS model (green and red). (b) Section view.

integrated fabrication model, members are prefabricated in factories, and construction is performed on the site as shown in Figure 15. If fabrication and construction are performed before the quality examination is completed, serious quality defects may occur. This process is different from those used in existing BIM application projects, in which design errors during construction are examined by converting 2D design drawings into $3 \mathrm{D}$ designs. For the precise implementation of 


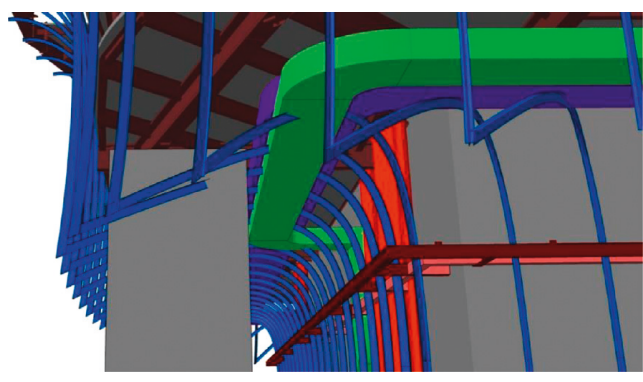

(a)

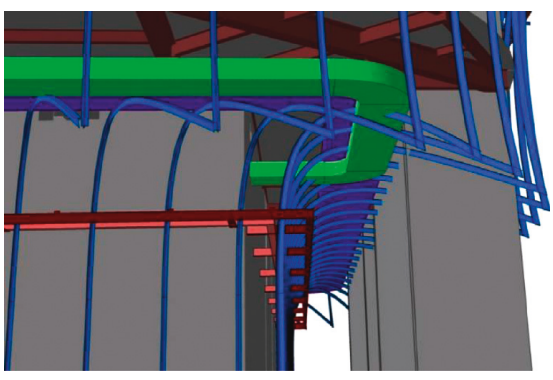

(b)

FIgURE 6: Clash detection between the secondary steel structure and MEP system.

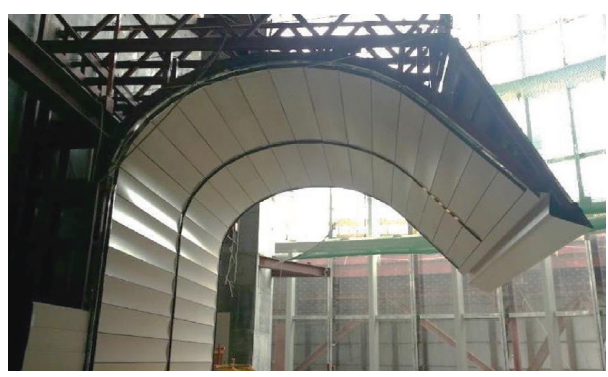

(a)

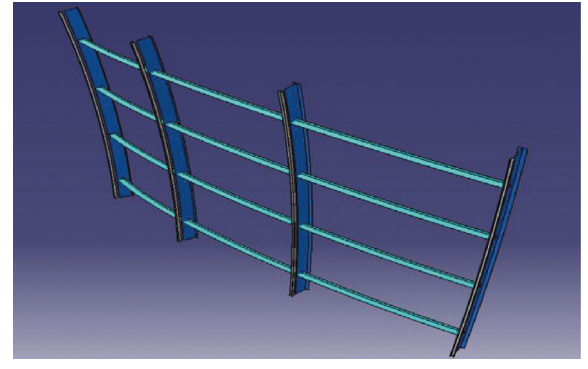

(b)

FIgURE 7: Free-form curved surface (a) and CNC T-BAR system (b).

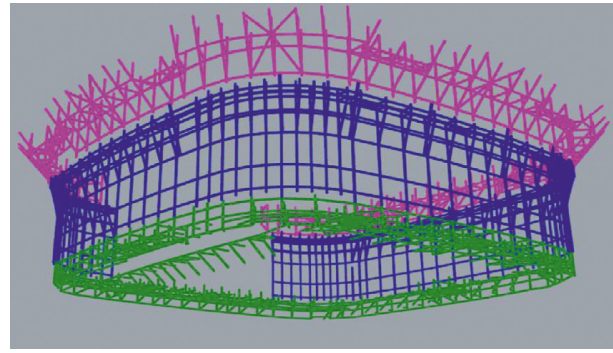

(a)

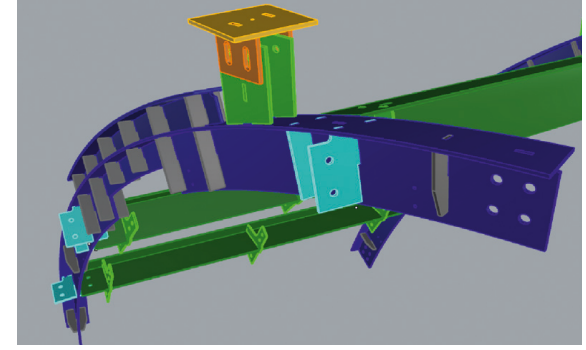

(b)

FIgURE 8: Fabrication model.

TABLE 2: List of prefabricated components.

\begin{tabular}{lcccc}
\hline Part & EA & Length/area & Duration (month) & Daily output (EA) \\
\hline Secondary structure & 3,115 & $8,855.87 \mathrm{~m}$ & 2 & 71.20 \\
T-BAR & 3,542 & $9,581.01 \mathrm{~m}$ & 3 & 53.67 \\
Form plate & 3,435 & $9,640.41 \mathrm{~m}$ & 3 & 52.05 \\
Reveal & 1,619 & $3,339.88 \mathrm{~m}$ & 4 & 24.53 \\
NT panel (10T) & 17,943 & $8,181.49 \mathrm{~m}^{2}$ (curved surface, plane, aperture) & 0.5 & 203.80 \\
Edge panel (1.6T) & 80 & $250.13 \mathrm{~m}$ & & 7.27 \\
\hline
\end{tabular}

the digital fabrication, errors must not occur in the production processes, such as manufacturing.

(3) Quality Control of Installed Parts. The quality inspection for the construction results of free-form surfaces was performed using 3D laser scanning. The professional construction companies managed the quality of installation by examining the data extracted from the survey data and integrated fabrication model.

\section{Results}

By analyzing the case in which the proposed digital fabrication process was applied to a free-form podium 


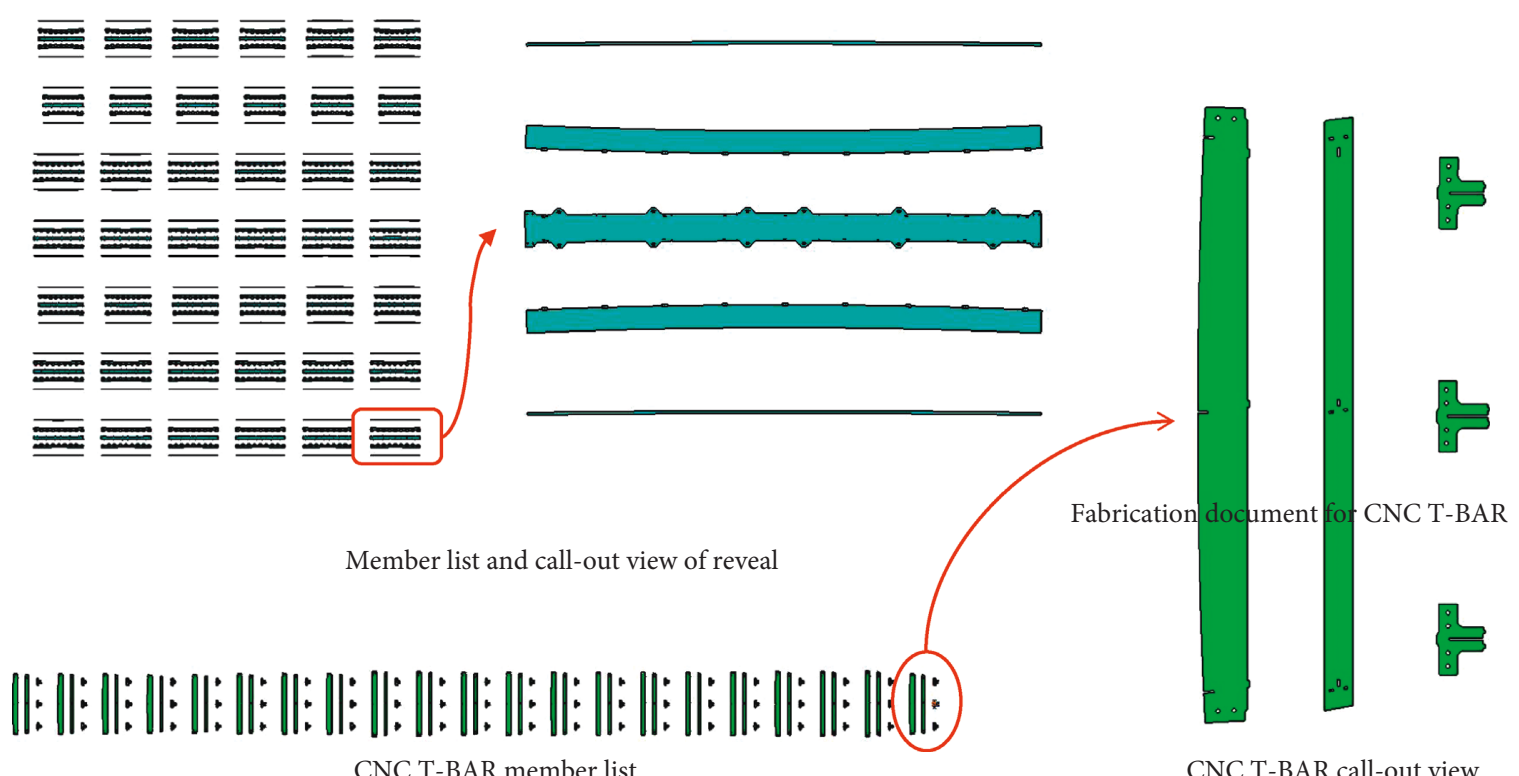

Figure 9: Planar figure example of CNC T-BAR and reveal.

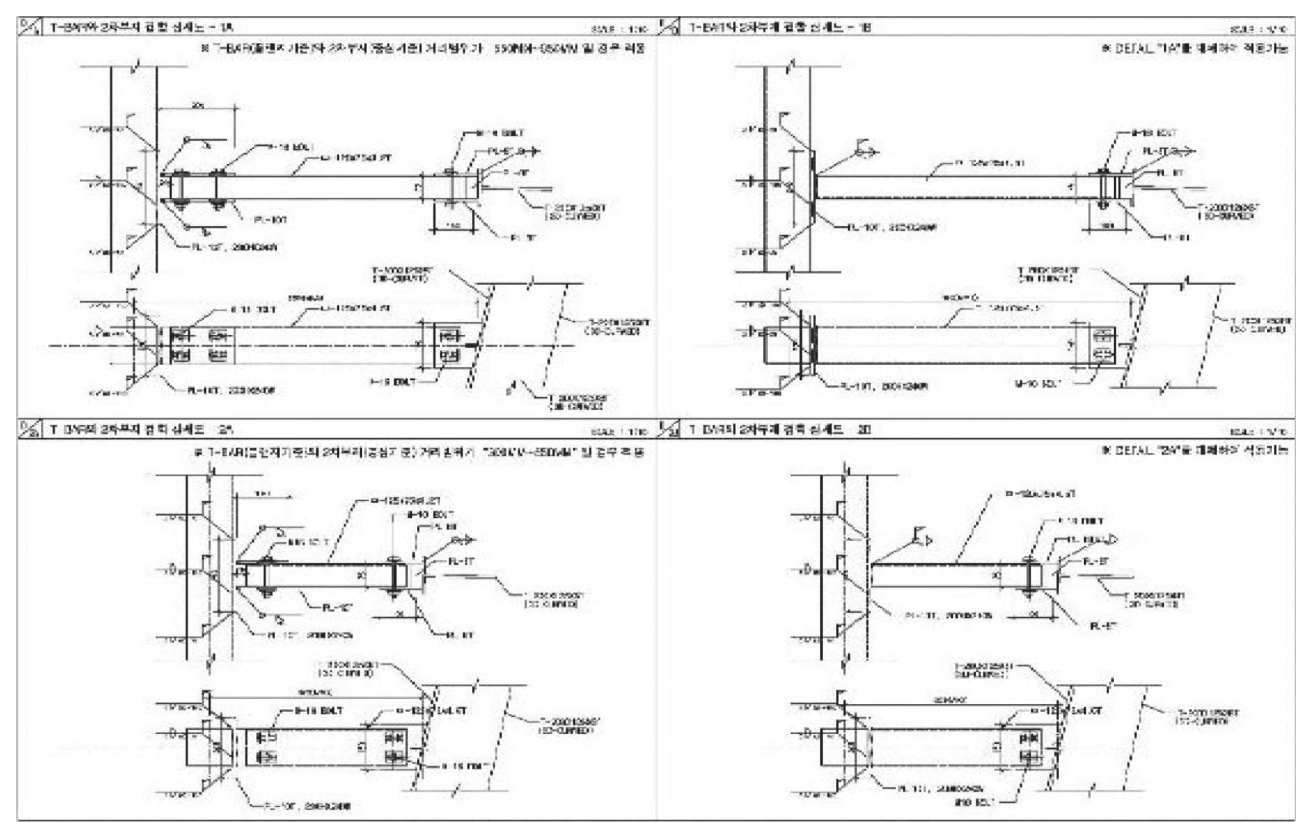

FIGURE 10: Fabrication shop drawings of CNC T-BAR and secondary steel structure extracted from the fabrication BIM model.

construction project, the unification, simplification, and automation levels of major tasks, such as automation design technology, fabrication drawing production automation technology, and construction quality control technology, were found to be more satisfactory than those of cases which are implemented through traditional BIM implementation methods (establishing the BIM model by using 2D drawings).

\subsection{Assessment of the Proposed Process}

\subsubsection{Condition Settings for the Evaluations}

(1) Multiserver Queuing Model (M/M/s). A digital fabrication company provides the contractor, subcontractor, and construction project manager participating in the construction with design and engineering models for fabrication and quality inspection. Therefore, in the queuing system, the company that provides the digital fabrication service becomes the server, and the contractor, subcontractor, and construction project manager that receive information from the server and participate in the construction of free-form parts become the customers. There are various queuing models depending on the probabilities of the arrival times of customers and the service time of the server. However, in this study, a multiserver queuing model was utilized, as shown in Figure 16, under the assumption that the digital fabrication company input multiple servers. 


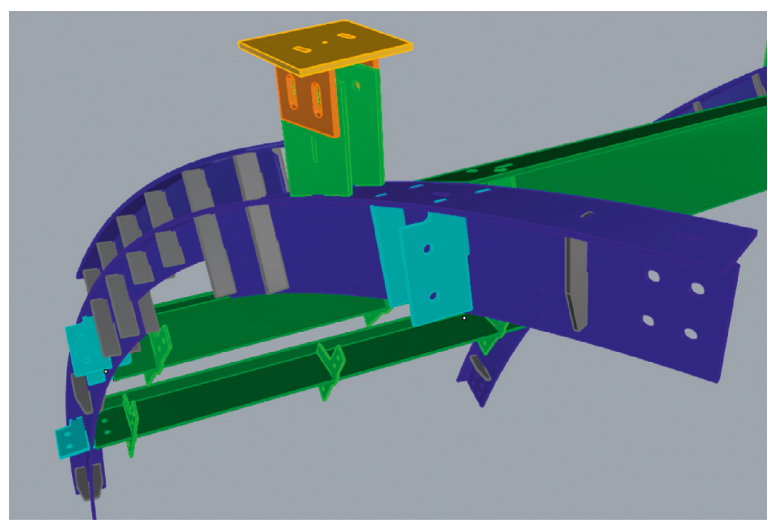

(i) Size: T-200X125X8T (SM490)

(ii) Number: $3,542 \mathrm{EA}(9,587.01 \mathrm{M})$

(iii) Fabrication method: $\mathrm{CNC}$ laser cutting and robot laser welding

(iv) Fabrication period: 3 months (installation: 4 months)

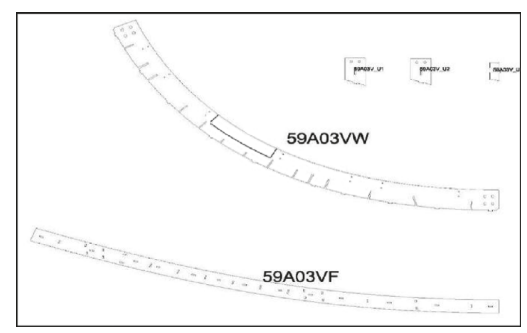

(b)

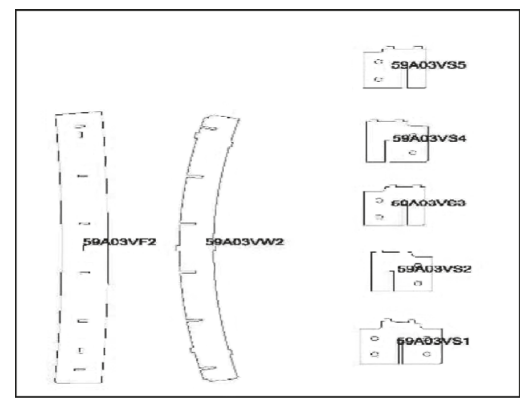

(c)

FIGURE 11: Fabrication information of a CNC T-BAR.

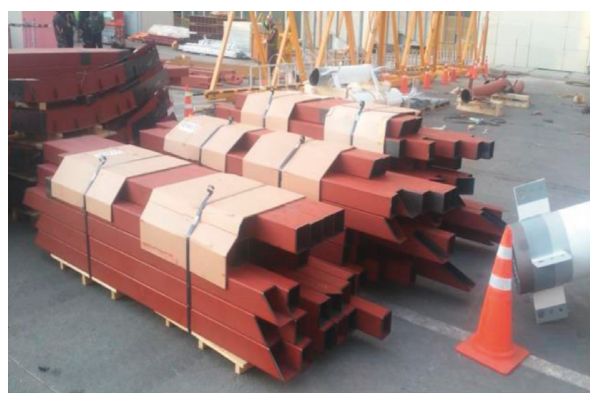

(a)

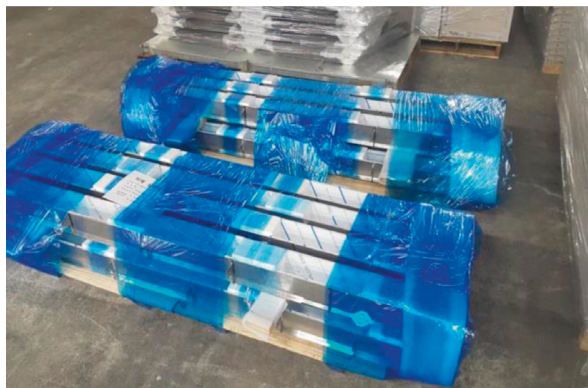

(c)

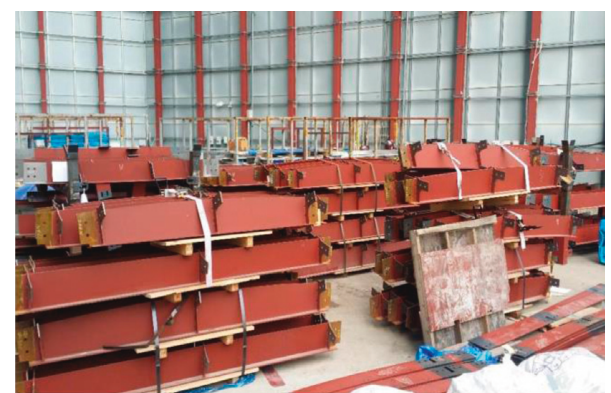

(b)

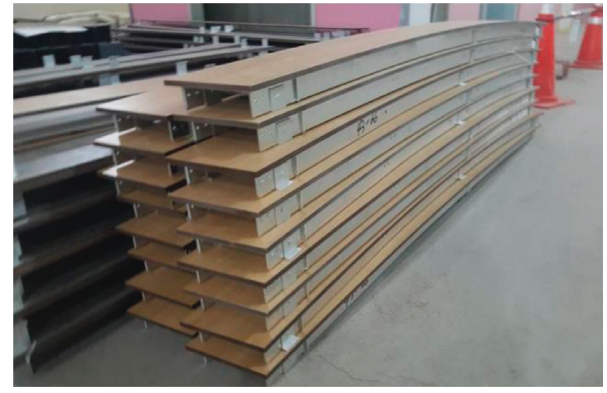

(d)

FIGURE 12: Warehousing of SSSs, T-BARS, reveals, and NT panels.

In the multiserver queuing model, the frequency with which the server, i.e., the digital fabrication company, receives a request for information on the construction of freeform parts is random. Considering this randomness, the time at which a customer arrives at the queue to receive the service is generally assumed to be an exponential distribution. In addition, the service time during which the information request of the customer is dealt with by the company is random, and the service time of the server is also assumed to be an exponential distribution [37]. Moreover, for most of the general BIM application construction projects, one BIM person stays on the site [40]. However, for the digital fabrication of free-form parts, multiple personnel are generally input because the input company can minimize 
TABLE 3: Member list and information samples for quality inspection of CNC T-BAR.

\begin{tabular}{|c|c|c|c|c|c|c|c|}
\hline \multirow{2}{*}{ Product no. } & \multicolumn{3}{|c|}{ Start (top or left) } & \multicolumn{3}{|c|}{ End (bottom or right) } & \multirow{2}{*}{ Straight line $(\mathrm{mm})$} \\
\hline & $x 1$ & $y 1$ & $z 1$ & $x 1$ & $y 1$ & $z 1$ & \\
\hline 401IN1 & 20,917 & 15,879 & 17,754 & 19,537 & 18,911 & 17,382 & 3,352 \\
\hline $401 \mathrm{IN} 2$ & 17,598 & 17,725 & 15,236 & 17,598 & 19,264 & 17,047 & 2,377 \\
\hline 402HD & 20,950 & $-9,629$ & 17,763 & 20,950 & $-12,775$ & 17,763 & 3,145 \\
\hline $402 I N 1$ & 17,661 & 19,386 & 17,179 & 19,445 & 18,998 & 17,367 & 1,836 \\
\hline 410AV & 26,382 & 12,636 & 19,235 & 26,382 & 12,636 & 16,300 & 2,935 \\
\hline 410BR11 & 25,542 & 14,302 & 17,763 & 26,043 & 15,663 & 17,763 & 1,450 \\
\hline 410BR11 & 25,542 & 14,302 & 17,763 & 26,043 & 15,663 & 17,763 & 1,450 \\
\hline 410BR12 & 24,982 & 12,780 & 17,763 & 25,483 & 14,141 & 17,763 & 1,450 \\
\hline
\end{tabular}
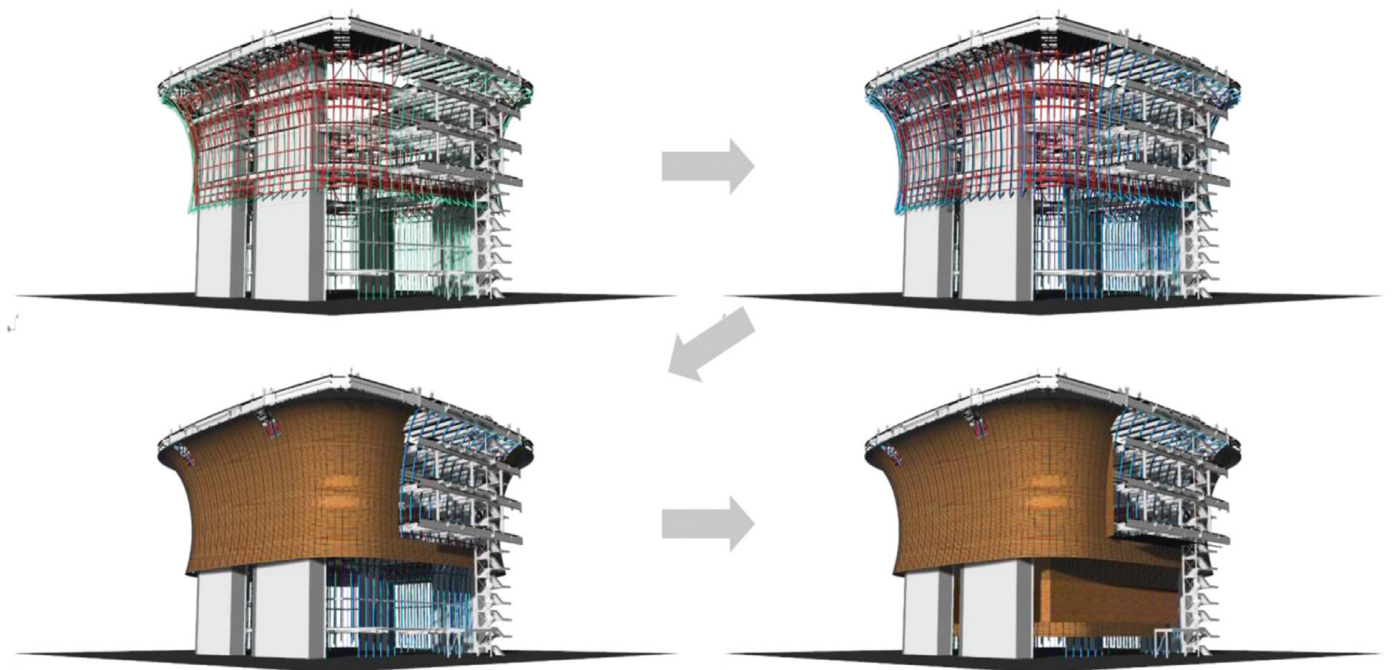

FIgURE 13: Construction simulation $\left(1^{\text {st }}:\right.$ SSS and CNC T-BAR; $2^{\text {nd }}:$ reveal; $3^{\text {rd }}$ : high-level NT panel; $4^{\text {th }}$ : edge and low-level NT panel).
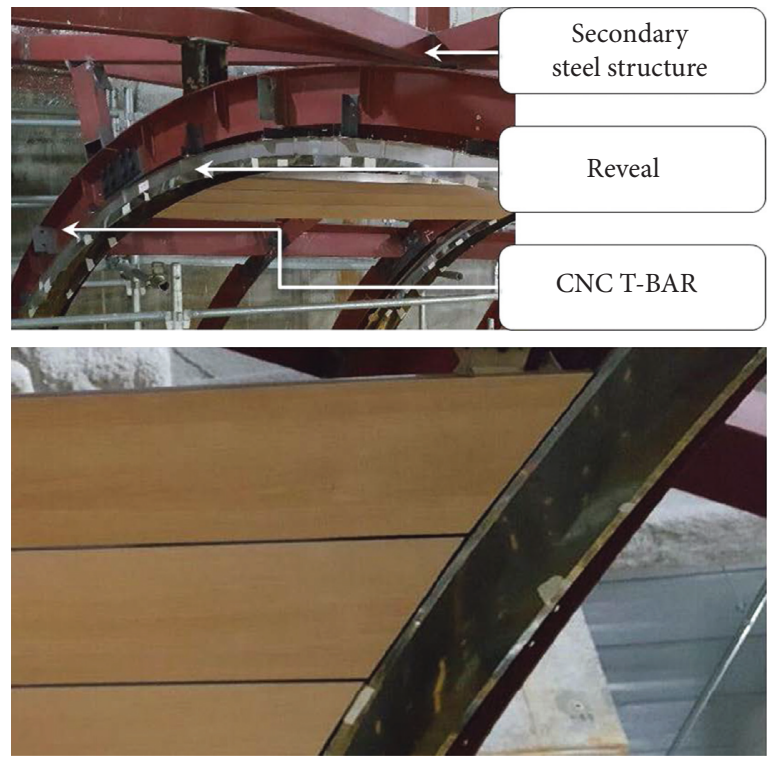

(a)

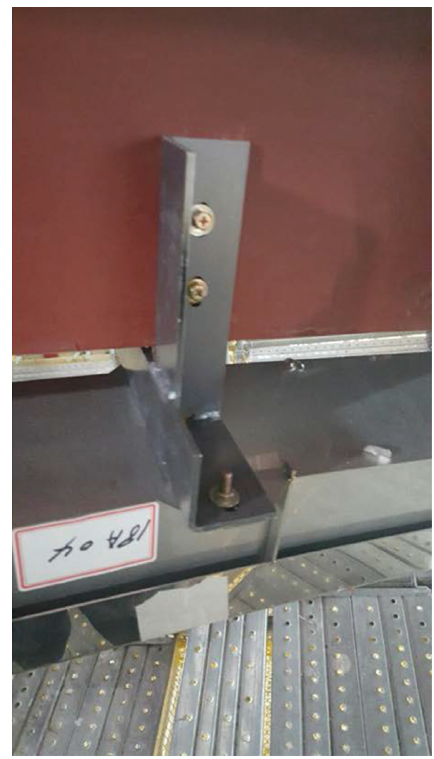

(b)

FIgURE 14: $1: 1$ mock-up. 


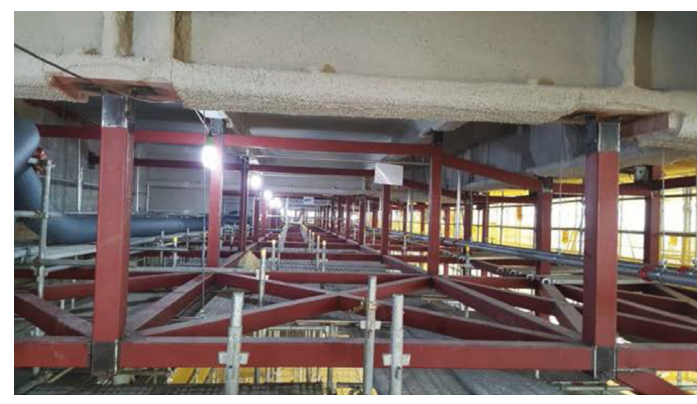

(a)

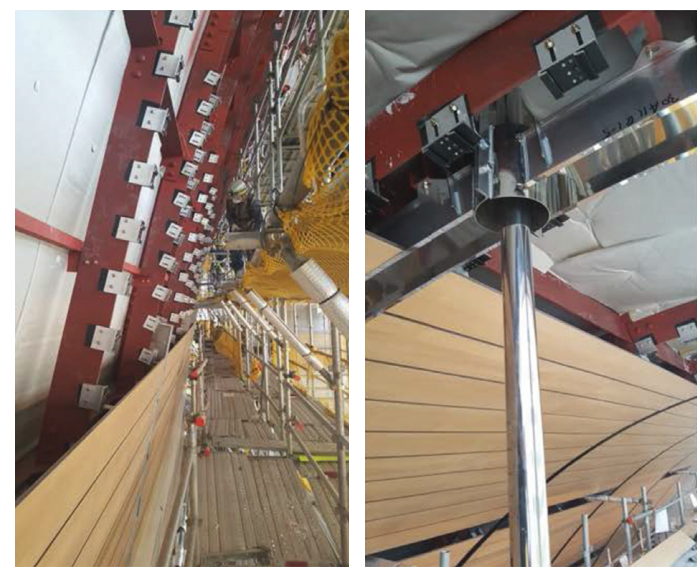

(c)

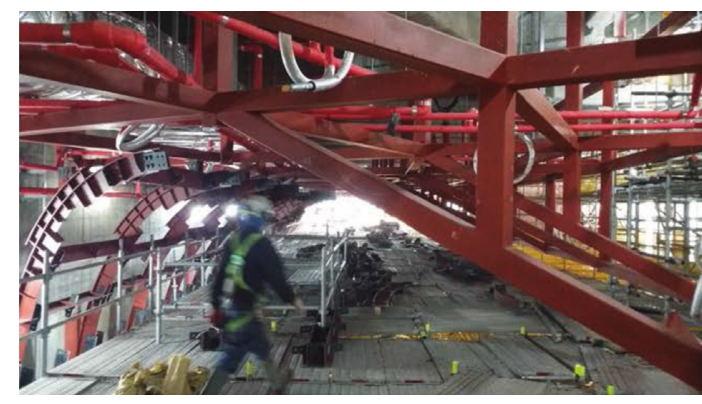

(b)
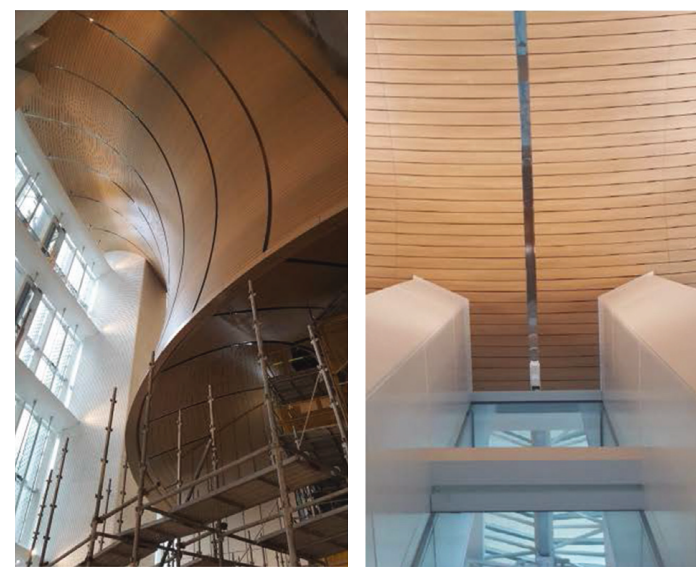

(d)

Figure 15: Site installation: (a) secondary steel structure; (b) CNC T-BAR; (c) NT panel; (d) finished status.

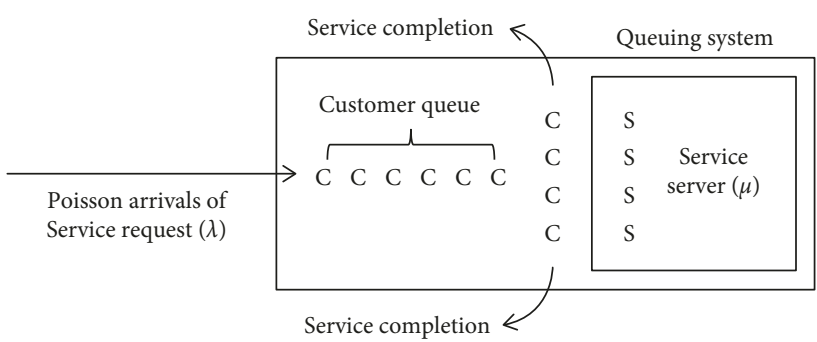

FIGURE 16: Multiserver queuing system ("C" represents a customer and "S" a server).

effects on subsequent processes when it completes its work within a short period of time. Therefore, the multiserver queuing model includes the following assumptions:

(i) The interarrival times follow an exponential distribution with an average of $1 / \lambda$

(ii) The service time follows an exponential distribution with an average of $1 / \mu$

(iii) The queuing system has s servers

(iv) The server utilization rate $(\rho)$ is defined as $\lambda / s \mu$

(v) The queuing system is infinite

(vi) The queuing service rule: FCFS (first come, first served)

5.2. Performance Indicators. When the performance of the construction companies that specialize in digital fabrication is analyzed through the multiserver queuing model, it is possible to analyze basic performance measures for the number of customers and waiting time, as shown in Figure 17, and perform probability analysis for the number of customers and waiting time in the queuing system.

5.2.1. Basic Performance Measure Analysis. The performance of the queuing system can be analyzed using the following two measures: (1) How many customers are generally waiting in the queuing system? (2) How long do the customers generally wait? These two measures are generally expressed with mean values (expected values). Four specific performance measures can be defined based on whether only the customers in the queue or all customers in the queuing system will be considered:

(i) $L=$ the average number of customers in the system including those in service

(ii) $L_{\mathrm{q}}=$ the average number of customers in the queue excluding those in service

(iii) $W=$ the average waiting time of each customer in the system (including the service time)

(iv) $W_{\mathrm{q}}=$ the average waiting time of each customer in the queue (excluding the service time)

The basic equations for deriving the performance measures of the multiserver queuing model $\left(L, L_{\mathrm{q}}, W, W_{\mathrm{q}}\right)$ are shown below: 


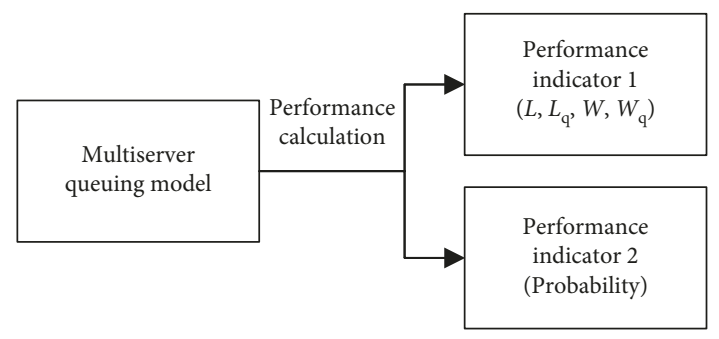

Figure 17: Performance calculation.

$$
\begin{aligned}
P_{0} & =\frac{1}{\sum_{n=0}^{s-1}\left((\lambda / \mu)^{n} / n !\right)+\left((\lambda / \mu)^{s} / s !\right)(1 /(1-\lambda / s \mu))} \\
L_{\mathrm{q}} & =\frac{P_{0}(\lambda / \mu)^{s} \rho}{s !(1-\rho)^{2}}=\frac{P_{0} \lambda^{s+1}}{(s-1) ! \mu^{s-1}(s \mu-\lambda)^{2}}, \\
W_{\mathrm{q}} & =\frac{L_{\mathrm{q}}}{\lambda}, \\
W & =W_{\mathrm{q}}+\frac{1}{\mu} .
\end{aligned}
$$

The most important formula for calculating the basic performance measures in the queuing model is Little's formula, which represents the direct relationship between $L$ and $W$, as shown in (2) [48]. Equation (2) also applies for $L_{\mathrm{q}}$ and $W_{\mathrm{q}}$. Thus, if either $L, L_{\mathrm{q}}$ or $W, W_{\mathrm{q}}$ is analyzed, the other performance measures can be immediately obtained. This enables a basic status analysis of the service to be performed.

$$
L=\lambda W(\lambda: \text { mean arrival rate }) .
$$

5.2.2. Probability Analysis for the Number of Customers and Waiting Time in the System. Through the queuing model, a probability analysis for the status of the queuing system, including the number of customers in the system and waiting time, is possible. If the server utilization rate $(\rho)$ is high, the system condition may deteriorate, and costs may result owing to waiting time increases. If this waiting cost is relatively higher than the server input cost, problems with economic efficiency may occur. In the case of free-form building projects, severe problems with quality may occur in addition to problems with economic efficiency. Therefore, the performance of the company must be evaluated by predicting how many customers are in the queuing system on a probabilistic basis. $P_{n}$ represents the probability of a stable state when there are $n$ customers in the system:

$$
\begin{aligned}
& P_{n}=C_{n} P_{0}, \\
& C_{n}=\frac{\lambda_{n-1} \lambda_{n-2} \ldots \lambda_{0}}{\mu_{n} \mu_{n-1} \ldots \mu_{1}}= \begin{cases}\frac{(\lambda / \mu)^{n}}{n !}, & n=1,2, \ldots, s, \\
\frac{(\lambda / \mu)^{n}}{s ! s^{n-s}}, & n=s+1, S+2, \ldots\end{cases}
\end{aligned}
$$

The probability of the waiting time of a customer in the system $(t)$ can be expressed as follows. Equation (4) represents the probability that the waiting time of a customer in the system is longer than $t$, and equation (5) represents the probability that the waiting time in the queue is longer than $t$ :

$$
P(W>t)=e^{-\mu t}\left[1+\frac{P_{0}(\lambda / \mu)^{s}}{s !(1-\rho)}\left(\frac{1-e^{-\mu t(s-1-\lambda / \mu)}}{s-1-\lambda / \mu}\right)\right]
$$

$$
P\left(W_{\mathrm{q}}>t\right)=\left(1-\sum_{n=0}^{s-1} P_{n}\right) e^{-s \mu(1-\rho) t}
$$

5.3. Data Collection for Analyzing Quantitative Project Performance and the Queuing Model. In the case project, the members produced through the fabrication drawings provided by the digital fabrication company are listed in Table 3. In the case of the aperture NT panel, if it is assumed that one fabrication drawing in the form of a planar figure is required for one member, as fabrication drawings for the front and rear processing are required, a total of 36,274 fabrication drawings must be created. During the total service period of seven months, nine engineers from professional construction companies were input (one professional engineer, one special engineer, one advanced engineer, four intermediate engineers, and two beginner engineers). Detailed information is presented in Table 4.

It was found that they participated in the project for a total of $6,574 \mathrm{~h}$ during the period of seven months. As the nine workers also participated in projects different from this case project, a total of 52,441 fabrication drawings could have been produced arithmetically had they participated in this case project on a full-time basis (a total of 9,504 h). Based on these data, the daily mean arrival rate $(\lambda)$ for the fabrication drawing request becomes $274.80(=36,274$ copies of drawings/132 day for six months). If this is converted based on the number of the personnel, the mean arrival rate $(\lambda)$ is $30.53(=274.80 / 9)$. Using the assumption that the nine engineers work on a full-time basis, the daily mean service rate $(\mu)$ becomes 340.53 . If this is converted based on the number of workers, the mean service rate $(\mu)$ becomes 37.84. Accordingly, the server utilization rate $(\rho=\lambda / s \mu)$ is calculated to be $0.81(=274.80 /(9 * 37.84))$. In addition, the server idle rate, $(1-\rho)$, is calculated to be 0.19 .

This means that the digital fabrication process is active only $81 \%$ of the time. The remainder of the time is utilized for performing other tasks explained above. This includes a month of preparation period, work plan, and environment establishment for the professional construction company responsible for the digital application work before the contract. In detail, the establishment work of the fabrication BIM model is included in the fabrication documentation work (6 months). Furthermore, initial preparation and quality control for drawing extraction are included in the drawing extraction work (6 months), and thus, the 19\% server idle rate is by no means too high and is one of the works that must be performed. 
TABLE 4: Input manpower for digital fabrication works.

\begin{tabular}{lcccccc}
\hline Month & & \multicolumn{5}{c}{ Worker level } \\
& Professional & Special & Advanced & Intermediate (total hours for 4 workers) & Beginner (total hours for 2 workers) & Total hours \\
\hline $1^{\text {st }}$ month & 92 & 120 & 256 & 446 & 86 & 226 \\
$2^{\text {nd }}$ month & 145 & 194 & 249 & 554 & 212 & 1,020 \\
$3^{\text {rd }}$ month & 28 & 120 & 229 & 173 & 296 & 763 \\
$4^{\text {th }}$ month & 25 & 214 & 262 & 594 & 390 & 1,391 \\
$5^{\text {th }}$ month & 20 & 228 & 192 & 600 & 167 & 1,430 \\
$6^{\text {th }}$ month & 22 & 104 & 222 & 88 & 1,281 & 603 \\
Total (h) & 332 & 980 & 1,410 & 2,475 & 6,574 \\
\hline
\end{tabular}

\subsection{Performance Measurement Model Analysis Results}

5.4.1. Basic Performance Measure Analysis. As a result of analyzing the average performance of nine personnel input for digital fabrication, the server utilization rate $(\rho=\lambda / s \mu)$ was 0.81 , a value less than 1 , which is the requirement for the queue to reach the stable state. This indicates that the professional construction companies can provide normal services to customers in need of fabrication drawings in the queuing system. As for the basic performance measures, $L$ was 9.13 cases, $L_{\mathrm{q}}$ was 1.87 cases, $W$ was $0.03 \mathrm{~d}$, and $W_{\mathrm{q}}$ was $0.01 \mathrm{~d}$. Thus, the average waiting time of a customer is approximately $0.24 \mathrm{~h}(14.4 \mathrm{~min})$, which is 0.03 of a day (based on $8 \mathrm{~h}$ ).

\subsubsection{Probability Analysis for the Number of Customers and} Waiting Time. In the queuing system, $P_{n}$ represents the probability that during the stable state, there are $n(n=1,2,3, \ldots)$ customers in the system. Figure 18 shows the probability according to the number of fabrication drawings in the queuing system of the case project.

If the goal is to maintain the requests for fabrication drawings to less than 15 cases in the queuing system over $90 \%$ of the time, the equation $P_{0}+P_{1}+\cdots+$ $P_{15}=0.9003 \geq 0.90$ is valid. The value of $P_{0}$ was 0.0005 , indicating that this queuing system is always waiting for fabrication drawing production. As shown in Figure 18, the value of $P_{7}$ is the highest at 0.1180 , followed by $P_{6}(0.1137)$, $P_{8}(0.1071), P_{5}(0.0940)$, and $P_{9}(0.0864)$. However, a customer did not wait long in most cases because nine servers were input. This means that the professional construction companies can provide information in time without customers having to wait. There was almost no waiting time for the service to request and receive fabrication drawings because the fabrication drawing production method was automated through the integrated fabrication model described above.

The probability that the waiting time of a customer has a certain value was analyzed to more accurately judge the productivity of the project. The probability of waiting $10 \mathrm{~min}$ or longer was analyzed. As a result, $P(W>t)$ was 0.5762 , indicating that the probability of waiting $10 \mathrm{~min}$ or longer in the queuing system to receive fabrication drawings was $57.6 \%$. Moreover, $P\left(W_{\mathrm{q}}>t\right)$ was 0.1137 , indicating that the probability of waiting $10 \mathrm{~min}$ or longer in the queue to receive fabrication drawings was $11.37 \%$. This means that a customer does not wait for long to receive fabrication drawings and that the service status for providing fabrication drawings is excellent.

5.5. Comparative Analysis of the Work Productivities of the Proposed and Conventional Methods. Existing case analysis studies were utilized to compare the productivity of the proposed digital fabrication process with that of the conventional method $[40,49]$. Table 5 presents the BIM conversion design personnel input in various studies. While BIM personnel were inputted in the construction phase and performed BIM-related requests for information (RFIs), the digital fabrication company was input during a short period of time for the construction of the free-form podium region. Owing to the nature of the construction, high-level engineering and project management capabilities, such as structural system selection, discussion of other processes, and detail determination, are required despite completion of the free-form construction. Moreover, the determined work period must be followed because subsequent processes can be significantly affected. Although the man/month inputs of the conventional and proposed methods are similar, there are considerable differences in work performance. The BIM personnel supporting the design conversion respond to the RFIs of the project participants, and they are focused on improving the consistency of the BIM model during the remaining time. However, for cases where free-form projects require tens of thousands of fabrication drawings, improving the consistency of the BIM model is not the goal. The focus is on achieving zero errors in the final implementation through the information extracted from the BIM model to ensure construction quality. Therefore, digital technology must be aggressively utilized to implement precise construction quality and produce the tens of thousands of fabrication drawings required for short-term construction. In other words, the automation design technology was aggressively introduced to construct an integrated BIM model capable of providing information on the design, fabrication, and construction within a very short period of time. Furthermore, the application of the BIM model was done at a very high level by performing factory fabrication through the technology to automatically produce tens of thousands of fabrication drawings from the BIM model and manage the construction quality.

When the performance of the BIM personnel utilizing the multiserver queuing model is compared with the existing 


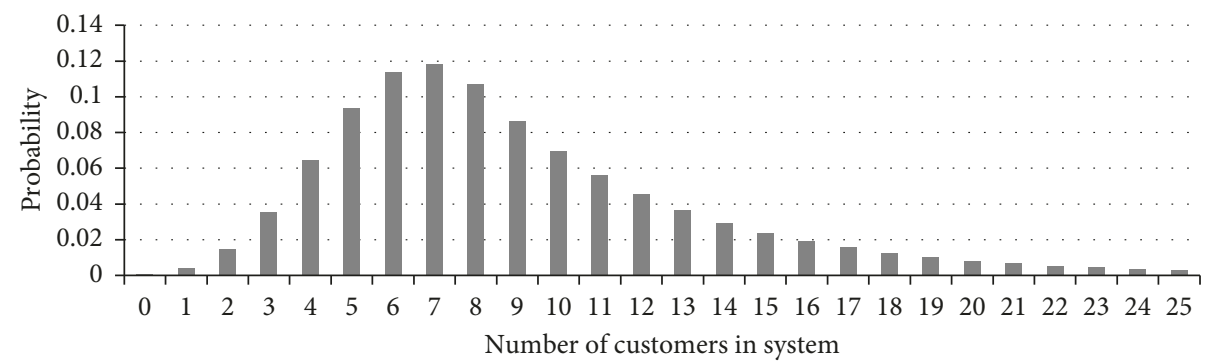

FIGURe 18: Probability of the number of BIM RFIs in the queuing system.

TABLE 5: Comparison of labor input and findings.

\begin{tabular}{lcccc}
\hline Category & BIM labor [49] & BIM labor [40] & Specialty contractor $(6,574$ h) & Specialty contractor $(9,504$ h) \\
\hline Period (M) & 20 & $13-17$ & 7 & 7 \\
No. of workers & 1 & $1-3$ & 9 & 9 \\
\hline Finding & & BIM RFI & & Fabrication documentation \\
\hline No. of findings & 244 & $214-381$ & 36,274 & 52,441 \\
\hline
\end{tabular}

study cases, the high performance of the professional construction companies of this study can be observed objectively (Table 6). Kim et al. [40] analyzed performance of BIM-based digital fabrication using the RFIs supported while the BIM personnel remained at the site for the construction phase of the BIM application project (case projects $1-4$ in Table 6$)$. The mean arrival rate $(\lambda: 0.748-1.094)$ and mean service rate $(\mu: 1-3)$ were extremely low compared to the mean arrival rate $(\lambda: 26.17)$ and mean service rate $(\mu$ : 37.84 ) of the professional construction companies. This is because the number of the fabrication members required in the course of implementing the shapes of free-form curved surfaces $(36,274)$ was higher than the BIM RFIs. Such results were obtained even though the company did not work on a full-time basis. If the company had worked on a full-time basis and if BIM technology was utilized at a very high level, such as for automation design, automatic fabrication drawing production, and factory fabrication based on $3 \mathrm{D}$ model information, 52,441 fabrication drawings could have been produced.

\section{Discussion}

In general, conventional fabrication methodologies have relied on 2D CAD and numerous paper documents, which have caused various problems, such as difficulties and errors in design, poor fabrication quality, and increased construction difficulty. BIM, which is a simple support technology, has been applied to supplement these processes. However, the BIM data cannot be used to manage the entire life cycle of the project, including the design, fabrication, and installation phases. In particular, it is difficult to obtain effects such as cost reduction, schedule reduction, and information provision to improve work productivity throughout the production life cycle.

The BIM-based digital fabrication proposed in this study is a methodology for steadily managing and utilizing a single set of BIM data throughout the entire life cycle of the project, from the initial stage to the construction and quality control stages. To determine the quantitative effect of the proposed digital fabrication process, the amount of work performed in relation to the personnel and time input, i.e., the performance, was analyzed. The resulting values of mean independent rate $(\mu)$, mean service rate $(\mu)$, server efficiency $(\rho / s \mu)$, and server efficiency $(1-\rho)$ proved that the proposed process exhibits satisfactory performance.

This means that the proposed BIM-based digital fabrication service is very efficient in providing the right information to the right participants in the design, fabrication, and construction work. To optimize the process through digital communication, it is necessary to produce and provide high-level and effective information. These tasks can be produced through BIM and automation technologies, and the man/months carrying them out are not significantly different from the existing personnel. In other words, this study reveals that by improving the process, considerable improvements can be achieved without increasing manpower or time.

\section{Conclusions}

7.1. Study Summary. In this study, a digital fabrication process during the life cycle of a building project was proposed based on the free-form podium construction case. The main steps are as follows:

(1) Free-form part shape optimization

(2) Structure system selection for NT panel shape control

(3) Fabrication drawing production

(4) Digital manufacturing

(5) Material receipt and inspection

(6) Construction and measurement

The proposed process is a generalized model that can be universally applied even though the characteristics of digital 
TABLE 6: Comparison of performance indicators in the queuing model.

\begin{tabular}{lccccc}
\hline \multirow{2}{*}{ Performance indicators } & \multicolumn{2}{c}{ Case projects [40] } & Specialty contractor $(9,504 \mathrm{~h})$ \\
\hline Period (day) & Project 1 & Project 2 & Project 3 & Project 4 & 154 \\
No. of workers $(s)$ & 352 & 286 & 308 & 374 & 9 \\
Mean arrival rate $(\lambda)$ & 2 & 1 & 1 & 3 & 26.17 \\
Mean service rate $(\mu)$ & 1.082 & 0.748 & 1.094 & 0.826 & 37.84 \\
Server utilization $(\rho=\lambda / s \mu)$ & 2 & 3 & 1 & 1.67 & 0.81 \\
Server efficiency $(1-\rho)$ & 0.271 & 0.249 & 1.094 & 0.165 & 0.19 \\
\hline
\end{tabular}

fabrication might change owing to numerous variables, such as the target project, part, type, form, scale, and material. Moreover, a productivity evaluation model was proposed using the queuing model to verify the productivity of the case project implemented through the proposed process. Basic performance measures were verified, and the number of customers and waiting time probabilities were calculated using the multiserver queuing model as the basic framework. Through a comparison with the conventional 2D-based fabrication and installation method, an improvement in productivity was demonstrated.

\section{Contributions}

The BIM-based digital fabrication methodology provides error minimization, time reduction, and collaboration efficiency reinforcement in performing tasks such as $3 \mathrm{D}$ fabrication, model construction, panel design automation, fabrication-drawing production automation, and 3D status measurement data examination for quality control. Moreover, it enables communication, collaboration, and coordination with construction companies, construction project managers, and professional construction companies hired for the construction of free-form exterior panels and low structural members using BIM data.

The performance analysis, based on a multiserver queuing model, provides a quantitative analysis methodology and uses data obtained throughout the project, such as the number of fabrication drawings, input personnel, input period, and input time. The results revealed that the professional construction companies performing digital fabrication could automatically produce the tens of thousands of fabrication drawings required for free-form shape implementation by applying various digital technologies that utilize $3 \mathrm{D}$ models and making these drawings available to the project participants. This proposed digital technology is different from design conversion, which converts the existing $2 \mathrm{D}$ design drawings into $3 \mathrm{D}$ models.

8.1. Limitations and Future Work. While this study focused on the performance of the personnel of professional construction companies, the productivity of the computers and robots utilized in the digital fabrication process were not considered. Had they been considered, the performance of digital fabrication would have been verified more specifically. Moreover, the cost of digital fabrication was not directly input into the analysis target, and it was indirectly reflected through the comparison of the service rate and waiting time. The limitations of these two factors will be analyzed in connection with the evaluation methodology based on the queuing model in a future study.

\section{Data Availability}

The data used to support the findings of this study are available from the corresponding author upon request.

\section{Conflicts of Interest}

The authors declare that there are no conflicts of interest regarding the publication of this paper.

\section{Acknowledgments}

This work was supported by the Korea Institute of Energy Technology Evaluation and Planning (KETEP) and the Ministry of Trade, Industry \& Energy (MOTIE) of the Republic of Korea (no. 20161510300420).

\section{References}

[1] O. Zwikael, Y. Cohen, and A. Sadeh, "Non-delay scheduling as a managerial approach for managing projects," International Journal of Project Management, vol. 24, no. 4, pp. 330-336, 2006.

[2] J. L. Celine, The evolution of the use of prefabrication techniques in Hong Kong construction industry, Ph.D. thesis, Hong Kong Polytechnic University, Hong Kong, China, 2009.

[3] V. R. Kamat, J. C. Martinez, M. Fischer, M. Golparvar-Fard, F. Peña-Mora, and S. Savarese, "Research in visualization techniques for field construction," Journal of Construction Engineering and Management, vol. 137, pp. 853-862, 2010.

[4] J. Lee and J. Kim, "BIM-based 4D simulation to improve module manufacturing productivity for sustainable building projects," Sustainability, vol. 9, no. 3, p. 426, 2017.

[5] McGraw Hill Construction, The Business Value of BIM for Construction in Major Global Markets: How Contractors around the World Are Driving Innovation with Building Information Modeling, H. M. Bernstein, Ed., SmartMarket Report, Bedford, MA, USA, 2014.

[6] R. S. Weygant, BIM Content Development: Standards, Strategies, and Best Practices, Wiley, Hoboken, NJ, USA, 2011, ISBN: 978-0-470-58357-9.

[7] N. Č. Babič, P. Podbreznik, and D. Rebolj, "Integrating resource production and construction using BIM," Automation in Construction, vol. 19, no. 5, pp. 539-543, 2010. 
[8] M. Hamid, O. Tolba, and A. El Antably, "BIM semantics for digital fabrication: a knowledge-based approach," Automation in Construction, vol. 91, pp. 62-82, 2018.

[9] C. B. Tatum, J. A. Vanegas, and J. M. Williams, Constructability Improvement Using Prefabrication, Preassembly, and Modularization, Bureau of Engineering Research, University of Texas at Austin, Austin, TX, USA, 1987.

[10] P. Paevere and C. MacKenzie, Emerging Technologies and Timber Products in Construction, Australian Forest and Wood Products Research and Development Corporation, Melbourne, Australia, 2006.

[11] S. McGuinness and J. Bennett, "Examining the link between skill shortages, training composition and productivity levels in the construction industry: evidence from Northern Ireland," International Journal of Human Resource Management, vol. 17, no. 2, pp. 265-279, 2006.

[12] G. Seaden and A. Manseau, "Public policy and construction innovation," Building Research \& Information, vol. 29, no. 3, pp. 182-196, 2001.

[13] A. Crowley, "Construction as a manufacturing process: lessons from the automotive industry," Computers \& Structures, vol. 67 , no. 5, pp. 389-400, 1998.

[14] D. Veeramani, H. P. Tserng, and J. S. Russell, "Computerintegrated collaborative design and operation in the construction industry," Automation in Construction, vol. 7, no. 6 , pp. 485-492, 1998.

[15] D. Gann, "Putting academic ideas into practice: technological progress and the absorptive capacity of construction organizations," Construction Management and Economics, vol. 19, no. 3, pp. 321-330, 2001.

[16] A. Agkathidis, J. Bettum, M. Hudert, and H. Kloft, Digital Manufacturing in Design and Architecture, BIS, Amsterdam, Netherlands, 2010.

[17] N. Dunn, Digital Fabrication in Architecture, Laurence King Publishing Ltd., London, UK, 2012.

[18] I. Agustí-Juan, F. Müller, N. Hack, T. Wangler, and G. Habert, "Potential benefits of digital fabrication for complex structures: environmental assessment of a robotically fabricated concrete wall," Journal of Cleaner Production, vol. 154, pp. 330-340, 2017.

[19] F. Gramazio and M. Kohler, Digital Materiality in Architecture, Lars Müller Publishers, Baden, Switzerland, 2008.

[20] F. Gramazio, M. Kohler, and S. Langenberg, FABRICATE: Negotiating Design \& Making, GTA Verlag, Zurich, Switzerland, 2014.

[21] S. H. Koh, N. H. Ham, J. S. Lee, S. W. Yoon, and J. J. Kim, "Comparison analysis of BIM level in the domestic and overseas BIM projects-focused on BIM journals and award winning projects," Journal of KIBIM, vol. 7, no. 2, pp. 25-35, 2017.

[22] J. S. Won, J. J. Lee, and G. Lee, "A case study on BIM collaboration and information management methods," Journal of the Architectural Institute of Korea Planning \& Design, vol. 24, no. 8, pp. 25-32, 2017.

[23] S. J. Jang and G. Lee, "Analysis of technical requirement for implementation of multi-trade prefabrication," Conference of the Korean Institute of Building Construction, the Korean Institute of Building Construction, vol. 16, no. 1, pp. 113-114, 2016.

[24] Skanska, Prefabrication Case Study, Miami Valley Hospital, NYC Healthcare Symposium, Philadelphia, PA, USA, 2011.

[25] Mortenson, "Prefabrication: benefits \& drivers for successful implementation," in Prefabrication Research Study Results,
M. Rosenquist and B. Gregor, Eds., SMACNA, Chantilly, VA, USA, 2014.

[26] W. C. Lim and J. K. Lee, "A study on expressive characteristics of pavilion applying digital fabrication," Journal of KISD, vol. 10, no. 6, 2015.

[27] L. Sass and M. Botha, "The instant house: a model of design production with digital fabrication," International Journal of Architectural Computing, vol. 4, no. 4, pp. 109-123, 2006.

[28] R. A. Buswell, R. C. Soar, A. G. F. Gibb, and A. Thorpe, "Freeform construction: mega-scale rapid manufacturing for construction," Automation in Construction, vol. 16, no. 2, pp. 224-231, 2007.

[29] S. Jang and G. Lee, "Process, productivity, and economic analyses of BIM-based multi-trade prefabrication-a case study," Automation in Construction, vol. 89, pp. 86-98, 2018.

[30] B. G. de Soto, I. Agustí-Juan, J. Hunhevicz et al., "Productivity of digital fabrication in construction: cost and time analysis of a robotically built wall," Automation in Construction, vol. 92, pp. 297-311, 2018.

[31] A. Fazel and A. Izadi, "An interactive augmented reality tool for constructing free-form modular surfaces," Automation in Construction, vol. 85, pp. 135-145, 2018.

[32] J. Knippers, "Integriertes Entwerfen im digitalen Prozess," Bautechnik, vol. 91, no. 4, pp. 257-261, 2014.

[33] X. Li, G. Q. Shen, P. Wu, H. Fan, H. Wu, and Y. Teng, "RBLPHP: simulation of lean construction and information technologies for prefabrication housing production," Journal of Management in Engineering, vol. 34, no. 2, article 04017053, 2018.

[34] M. Nahangi and C. T. Haas, "Automated 3D compliance checking in pipe spool fabrication," Advanced Engineering Informatics, vol. 28, no. 4, pp. 360-369, 2014.

[35] J. Wang, X. Wang, W. Shou, H.-Y. Chong, and J. Guo, "Building information modeling-based integration of MEP layout designs and constructability," Automation in Construction, vol. 61, pp. 134-146, 2016.

[36] H. Said, "Modeling and likelihood prediction of prefabrication feasibility for electrical construction firms," Journal of Construction Engineering and Management, vol. 142, no. 2, article 04015071, 2016.

[37] S. Frederick and S. Mark, "Introduction to management science," in A Modeling and Case Studies Approach with Spreadsheets, Chapter 11, McGrawHill, New York, NY, USA, 4th edition, 2010.

[38] N. K. V. Truong, Y. Choi, I. Kim, S. Shin, and W. J. Hwang, “A probabilistic approach to workflow time analysis for business process management," International Journal of Social Science Studies, vol. 5, no. 12, pp. 811-815, 2010.

[39] N.-H. Ham and J.-J. Kim, "A case study on BIM operating and performance measurement in construction phase," Journal of KIBIM, vol. 5, no. 2, pp. 1-11, 2015.

[40] H. J. Kim, M. Y. Yoo, J. J. Kim, and C. S. Choi, "Performance analysis of BIM labor using case analysis," Journal of KIBIM, vol. 7, no. 3, pp. 31-39, 2017.

[41] N. Sadeghi, A. Robinson Fayek, and N. Gerami Seresht, "Queue performance measures in construction simulation models containing subjective uncertainty," Automation in Construction, vol. 60, pp. 1-11, 2015.

[42] D. W. Halpin and S. L. Riggs, Planning and Analysis of Construction Operations, John Wiley and Sons, Hoboken, NJ, USA, 1992.

[43] J. Gerring, "What is a case study and what is it good for?," American Political Science Review, vol. 98, no. 2, pp. 341-354, 2004. 
[44] R. K. Yin, Case Study Research: Design and Methods, SAGE Publications, Newbury Park, CA, USA, 2nd edition, 1994.

[45] K. M. Eisenhardt, "Building theories from case study research," Academy of Management Review, vol. 14, no. 4, pp. 532-550, 1989.

[46] D. Holzer, The BIM Manager's Handbook: Guidance for Professionals in Architecture, Engineering, and Construction. Best Practice BIM ePart 1, Wiley, Hoboken, NJ, USA, 2015.

[47] S. J. Kim, Construction Method of $3 D$ Interior and Exterior Panel Using CNC T-BAR, Korea Intellectual Property Rights Information Service, Daejeon, South Korea, 2017.

[48] J. D. C. Little, "A proof of the queuing formula: $L=\lambda \mathrm{W}$," Operations Research, vol. 9, no. 3, pp. 383-387, 1961.

[49] E.-J. Kim, J.-H. Kim, and Y.-K. Huh, "A case study on practical uses of BIM in building construction," Journal of the Architectural Institute of Korea Structure \& Construction, vol. 32, no. 12, pp. 69-75, 2016. 


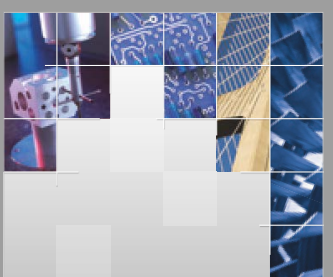

\section{Enfincering}
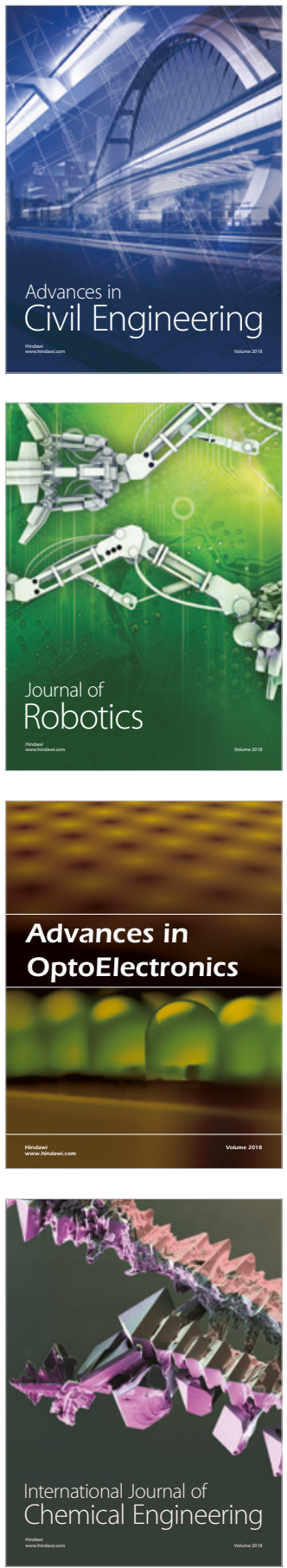

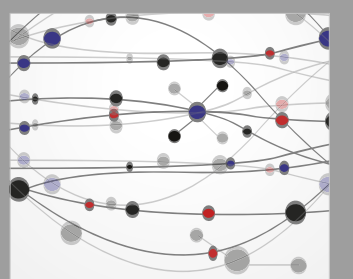

\section{Rotating \\ Machinery}

The Scientific World Journal

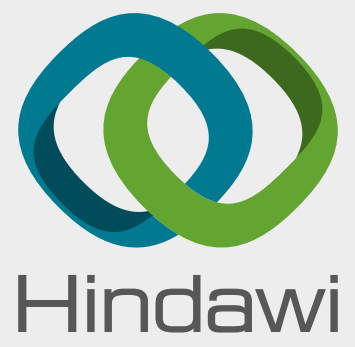

Submit your manuscripts at

www.hindawi.com
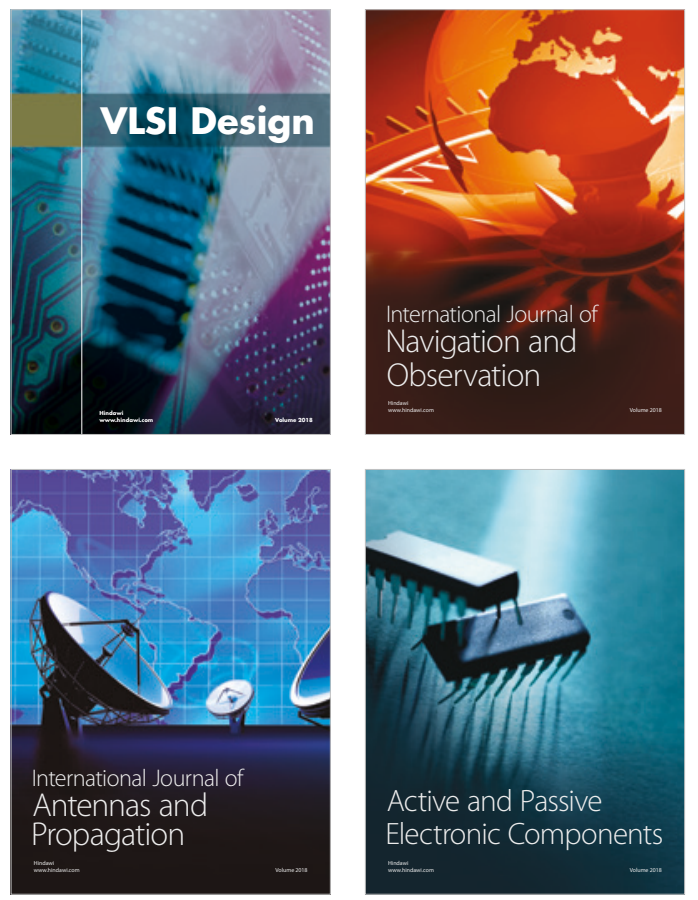
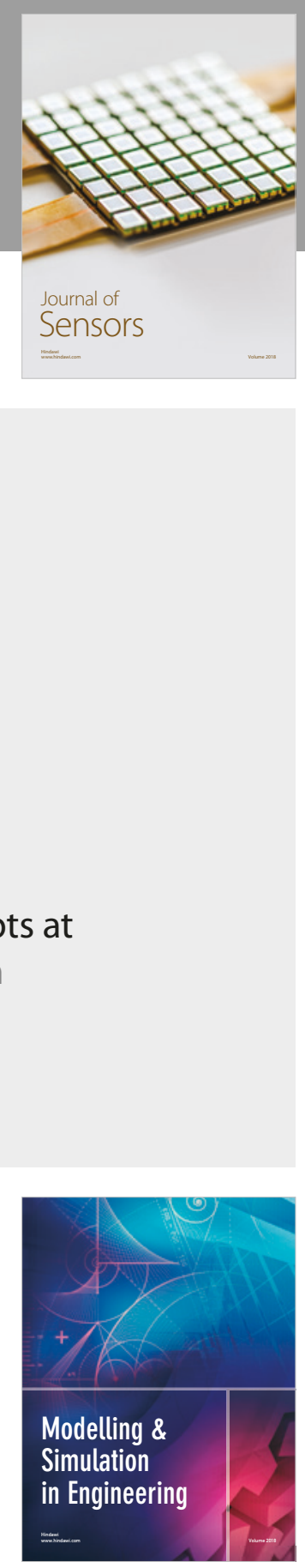

\section{Advances \\ Multimedia}
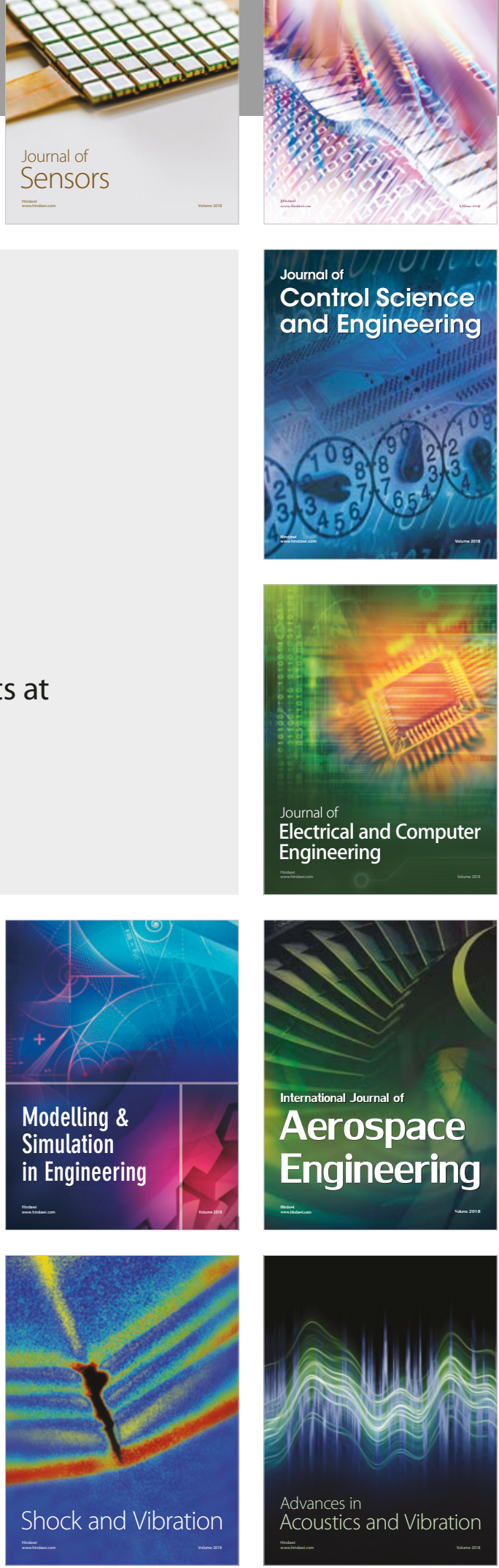